\title{
CHARACTERISATION OF AN ANALOGUE LIQUID FOR HYDRODYNAMIC STUDIES OF GAS-IONIC LIQUID FLOWS
}

\author{
Barry J. Azzopardi ${ }^{a}$, Ezekiel O. Agunlejika ${ }^{a}$, Donglin Zhao ${ }^{a}{ }^{*}$, Ryuhei Kaji ${ }^{a}$, Buddhika N. \\ Hewakandamby ${ }^{\mathrm{a}}$ \\ a Faculty of Engineering, University of Nottingham, University Park, Nottingham NG7 2RD, \\ United Kingdom \\ ${ }^{\mathrm{b}}$ School of Engineering, London South Bank University, London, SE1 0AA, United Kingdom
}

\begin{abstract}
Ionic liquids are liquid salts at low temperatures (normally less than $100^{\circ} \mathrm{C}$ ). They are powerful solvents with very low vapour pressure. They have great potentials in many applications such as gas absorption and chemical synthesis. However, they are expensive. This limits extensive studies towards establishing phenomenological models. To address this limitation, an analogue liquid, with properties similar to an ionic liquid, has been identified which on the grounds of cost and safety appears to be suitable.

In this paper, the hydrodynamic behaviour of an ionic liquid in a bubble column is compared with those of water and other liquids with similar physical properties. Average gas holdup, bubble coalescence, bubble size and specific interfacial area with different liquids are examined. Gas hold-up was determined by monitoring the change of conductivity between two flush mounted rings. The differences in bubble size and coalescence are revealed by analysing the stills taken from a high speed video camera. The dominant flow pattern in a small diameter column with ionic liquids or other fluids having similar viscosity is slug flow. The small bubbles in the liquid slugs make a smaller contribution to the specific interfacial area than Taylor bubbles. It is observed that Taylor bubbles can coalesce. The hydrodynamics of an ionic liquid in a bubble column can be estimated from that of a fluid with similar physical properties.
\end{abstract}

Keywords:

Bubble columns; Ionic liquids; Viscous liquids; Gas holdup; Bubble size; Flow regimes

*Corresponding author.

E-mail address: Donglin.Zhao@1sbu.ac.uk (D. Zhao) 


\section{Introduction}

Ionic liquids, salts that occur in liquid form at temperatures of $<100^{\circ} \mathrm{C}$, have great attraction because of: (a) their very low vapour pressure; (b) their high capacity to absorb carbon dioxide. The first of these makes them extremely useful as solvents for chemical reactions, particularly when products have to be removed by evaporation. When the solvent is ionic liquid, only the products will be volatilised off. They have attracted a large amount of attention from the scientific community over the past two decades and have been successfully applied in many research areas including inorganic, organic, and catalytic synthesis [1]-[4], biochemistry [5], electrochemistry [6], analytical chemistry [7], chemical engineering [8], and material science [9]. It is noted that some of the ionic liquids suggested for these purposes, 1-ethyl-3methylimidiazolium ethylsulphate $\left[\mathrm{EMIM}_{[}\left[\mathrm{EtSO}_{4}\right] \quad[9]-[10]\right.$ and 1-butyl-3methylimidiazolium tetrafluoroborate $[\mathrm{BMIM}]\left[\mathrm{BF}_{4}\right][11]$ have viscosities of $\sim 100$ times that of water at around room temperature. Now, chemicals, like these ionic liquids, are very expensive to purchase or complex to manufacture in house. Following a literature search on possible liquids, several were identified as analogues for ionic liquids. One was chosen based on criteria of cost and safety. This was an aqueous solution of glycerol (83.7\%) and potassium chloride (1.3\%). This paper characterises the important parameters of this liquid as well as those of an ionic liquid [EMIM][EtSO 4 .

One of the simplest pieces of equipment for contacting gas and liquid is the bubble column. In these units, gas is injected into the bottom of a column of liquid. Despite of its simple structure, the phenomena occurring in the column are complex due to the very deformable nature of the gas/liquid interface. There is a substantial literature on flow and mass transfer on bubble columns including several textbooks [12]-[14]. Normally the flow is distinguished into two regimes, i.e., homogeneous and heterogeneous $[15,16]$ with a transition region in between. Homogeneous flow, occurring at lower gas flow rates, consists of smaller bubbles dispersed 
throughout the liquid which have similar size and velocity and hence there is little coalescence. In contrast, the heterogeneous regime at higher gas flow rates, has radial variation of bubble properties, the occurrence of smaller and bubbles and complex, large scale circulations. In columns of larger diameter, the bigger bubbles have a shape which is usually termed spherical cap bubble. When the bubble column diameter is small, the bubbles of heterogeneous flow can fill in the whole column cross section and form gas plugs (called slug flow). As the liquid viscosity is increased above the value for water, it has been seen that the propensity of bubbles to coalesce increases; it also causes overall gas holdup to decrease [17]. Even in large diameter columns, e.g., $240 \mathrm{~mm}$, slug flow is present if the viscosity is sufficiently high, i.e., $300 \mathrm{~Pa} \mathrm{~s}$ [18]. For the gas flow rates normally employed in industrial bubble column operations with liquids of lower viscosity, heterogeneous flow is the most usual flow regime.

The specific interfacial area or interfacial area per unit volume, $a$, is an important parameter in mass transfer calculations. However, it is usually considered together with the mass transfer coefficient, $k_{L}$, as $k_{L} a$. The two parts are affected by different length scales. The specific interfacial area is governed by the hydrodynamics of the column whilst the mass transfer coefficient is linked to the microscale around the bubbles. In determining the specific interfacial area, measurements are required of the distribution of bubble sizes as it tends to be determined from the expression proposed by Akita and Yoshida [19]:

$a=\frac{6 \varepsilon_{g}}{D_{32}}$

Where $D_{32}$ is the Sauter mean diameter of the bubble population and $\varepsilon_{g}$ is the overall gas holdup. This is based on the total volume of gas and liquid. A different expression was used by Zhang et al. [11]

$a=\frac{6 \varepsilon_{g}}{D_{32}\left(1-\varepsilon_{g}\right)}$ 
In this case the volume is based on just the liquid part of the mixture. Because of the low values of gas hold-up in the experiments of Zhang et al. [11] there is only little difference when the specific interfacial are is calculated using $\mathrm{Eq}(1)$ or (2) as $1-\varepsilon_{g} \sim 1$.

When larger bubbles are present, particularly those bullet-shaped ones, often called Taylor bubbles, which can occupy the greater part of the cross-section of the column, a different approach to model the specific interfacial area is more appropriate. In the liquid slugs between the large bubbles, Eq. (1) still applies. If the Taylor bubble is assumed to consist of a hemisphere and a cylinder with a flat bottom and that specific interfacial area is obtained using standard geometric relationships. The overall specific interfacial area is then determined from the weighted sum of the two parts:

$a=\frac{4 L_{T B} D_{T B}+D_{T B}^{2}}{\left(L_{T B}+L_{S}\right) D_{C}^{2}}+\frac{6 \varepsilon_{g S}}{D_{32 S}} \frac{L_{S}}{\left(L_{T B}+L_{S}\right)}$

Here, $L_{T B}$ and $L_{S}$ are the mean lengths of the Taylor bubbles and the liquid slugs, $D_{T B}$ is the diameter of the cylindrical part of the Taylor bubbles, $D_{C}$ is the diameter of the bubble column, $\varepsilon_{g} S$ and $D_{32 S}$ are the gas holdup in the liquid slug part of the flow and the Sauter mean diameter of the bubbles. The second term is the contribution of small bubbles in the liquid slug part of the flow. Akita and Yoshida [19] employed columns with a variety of sizes and many different liquids in their research. However, their experiments were limited to a maximum velocity of $60 \mathrm{~mm} / \mathrm{s}$ and their largest viscosity was only 20 times that of water. Now, from the correlations they presented it would be expected that the specific interfacial area for the ionic liquids mentioned above would only be $20 \%$ of that for water. Data presented in this paper are aimed at evaluation of this inference. The relationships between the gas flow rate and the bubble sizes, both small and large are established and then used to determine the specific interfacial area for both the ionic liquid [EMIM] $\left[\mathrm{EtSO}_{4}\right]$ and a second liquid of similar viscosity. The coalescence of the large Taylor bubbles and their implications for specific interfacial area are 
considered. The results obtained for the more viscous liquids presented here are discussed in the context of (lower viscosity) data available in the literature.

\section{Relationships characterising bubble behaviour}

Two of the most common arrangements used to produce fine bubbles are perforated plates and porous sinters. The former consists of a number of regularly spaced, small diameter holes drilled into the plate. A typical size for these orifices is $0.5 \mathrm{~mm}$ diameter [20], [21]. The porous type, which can be made of metal, plastic or glass, is produced by partially melting powders of these materials in a mould so that the particles fuse but leave passages in the sintered material through which fluids can pass [22]-[25]. The sizes of bubbles created at nozzles, such as the holes of a perforated plate at the bottom of a pool of liquid were originally modelled for the viscous [26] and inviscid [27] cases. Subsequently, Gaddis and Vogelpohl [28] considered the relevant forces related to the creation of bubbles. These are buoyancy and gas momentum which aid bubble removal and surface tension, drag and inertia which hinder the detachment. A balance of these forces can derive an equation for bubble diameter estimation where iterations are needed. An explicit equation for bubble size, however, can be obtained under the condition that the bubble size is mainly controlled by viscous, surface tension and inertia. The initial sizes of bubbles produced at a porous sinter injectors have been measured [25] for a variety of liquids starting from water and then lowering the surface tension and increasing the viscosity up to $0.016 \mathrm{~Pa} \mathrm{~s}$ by adding either isobutanol or glycerine. A correlating equation shown in Eq. (4) was presented which could predict their data within $\pm 15 \%$.

$\frac{D_{32}}{D_{S}}=7.35\left[\frac{R e^{0.1} F r^{1.8}}{W e^{1.7}}\left(\frac{D_{p}}{D_{s}}\right)^{1.7}\right]^{0.2}$ 
where

$R e_{s}=\frac{\rho u_{g s s} D_{s}}{\eta} ; F r=\frac{u_{g s s}^{2}}{g D_{s}} ; W e=\frac{\rho u_{g s s}^{2} D_{s}}{\sigma}$

$D_{p}$, is the size of the pores, $D_{s}$ is the diameter of the porous sinter (often of smaller diameter than that of the column into which it is inserted) and $u_{g s s}$ is the gas superficial velocity based on the cross-sectional area of the sinter unit.

The terminal velocities of bubbles also have regions which depend on drag, surface tension and inertia. Examples of the velocity/bubble diameter relationship for liquids used in the experiments reported here or from the literature data is given in Fig. 1. An equation considering all the three factors has been produced by Lin et al. [29]. This equation was non-dimensional equation which covers all three regions. It has been tested against experiments over a wide range on temperatures (affecting liquid viscosities) and pressures and excellent agreement is shown. Temperature has a significant effect on the viscosity of the liquid employed. The equation relates dimensionless velocity $\left(u^{*}=V_{T}\left(\rho_{l} / g \sigma\right)^{0.25}\right.$ to a dimensional bubble size $\left(d^{*}=\right.$ $\left.d\left(\rho_{l} g / \sigma\right)^{0.5}\right)$ and accounts for different types of liquids: whether aqueous or organic, single or multi-component and pure or contaminated.

$u^{*}=\left\{\left[\frac{d^{* 2}}{M o^{0.25} K_{b}}\left(\frac{\rho_{l}-\rho_{g}}{\rho_{l}}\right)^{1.25}\right]^{-n}+\left[\frac{2 c}{d *}+\left(\frac{\rho_{l}-\rho_{g}}{\rho_{l}}\right) \frac{d *}{2}\right]^{-0.5 n}\right\}^{-1 / n}$

In this $n=0.8$ for contaminated liquids

and $n=1.6$ for purified liquids

$c=1.2$ for single component liquids

and $c=1.4$ for multicomponent liquid

$K_{b}=\max \left(K_{b 0} M o^{-0.038}, 12\right)$

with $K_{b 0}=14.7$ for aqueous liquids 
and $K_{b 0}=10.2$ for organic liquids

Table 1 lists the relevant physical properties. The figure shows that, for liquids with viscosities close to water, there is a plateau for a range of bubble sizes which are found in many pieces of equipment. It also gives justification to the use of the simple equation of Harmathy [30] for bubble velocity - this does not depend on bubble size. For higher viscosities, the plateau does not exist and the curve goes directly from the drag to the inertial regions. The velocities are much lower. It is also obvious that the velocities for [EMIM] $\left[\mathrm{EtSO}_{4}\right]$ and for the aqueous solution of glycerol with $1.3 \%$ potassium chloride are very similar to each other for the same bubble diameter.

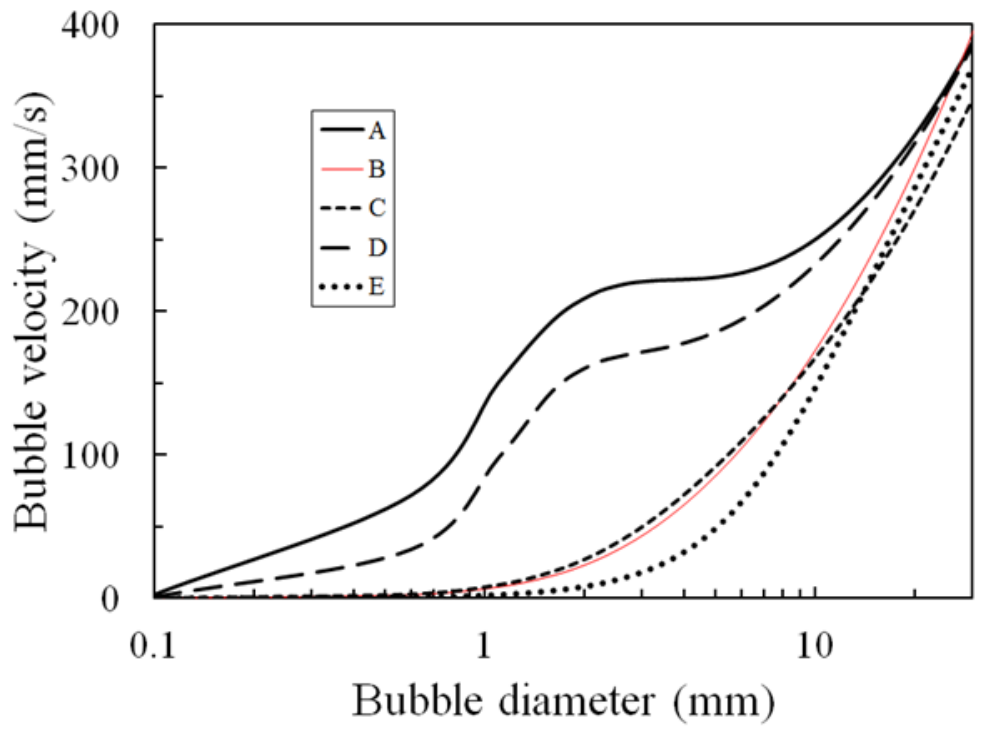

Fig. 1. Bubble velocities predicted from equation of Lin et al. [29]. A - Water;B [EMIM] $\left[\mathrm{EtSO}_{4}\right] ; \mathrm{C}-$ Aqueous solution of glycerol with $1.3 \%$ potassium chloride; $\mathrm{D}$ - Silicone oi with viscosity of $5 \mathrm{mPa} \mathrm{s}$; E- glucose water mixture with viscosity of $0.55 \mathrm{~Pa}$.

Clift et al. [31] published a map identifying the ranges of the dimensionless groups for which different types of bubbles exist. They reported that the effects of the channel walls become important when the bubble size reaches $6-12 \%$ of the channel diameter with the low end value applying for laminar flows $(\mathrm{Re}<0.1)$ and the high end one for $\mathrm{Re}>100$. Bubbles with diameters of greater than $60 \%$ of the channel diameter will be more of cylindrical shape and might be termed Taylor bubbles. Collins [32] provided a correction term in three parts which 
links velocities of more isolated bubbles to those filling the column. Subsequently, an alternative, a single continuous equation (tanh function) has been proposed [33]. As shown in Fig. 2, this latter gives a good representation of the original three part curves without any jumps. The asymptotic value, as bubble diameter approaches that of the column, is termed the Taylor bubble velocity. For water the original work of Dumitrescu [34] and Davies and Taylor [35] showed that this could be calculated from $\operatorname{Fr} \sqrt{g D}$ with the dimensionless velocity, $\operatorname{Fr}$ 0.35. Subsequent work showed that this is applicable for Archimdes numbers, Ar (= $\rho_{L}^{2} g D_{L}^{3} / \mu_{L}^{2)}>10000$. Ar $>10000$. For more viscous liquids Fr can be much smaller [36]. It is noted that for a gas hold-up of 0.05 , a velocity of the (probably) spherical cap bubble is $83 \%$ of that filling the entire column.

The above discussion is for single Taylor bubbles. If there is a continuous supply of gas and multiple bubbles, an additional term is required which depends on the gas flow rate. The velocity can be described as

$$
u_{T B}=C_{0} u_{g s}+F r \sqrt{g D}
$$

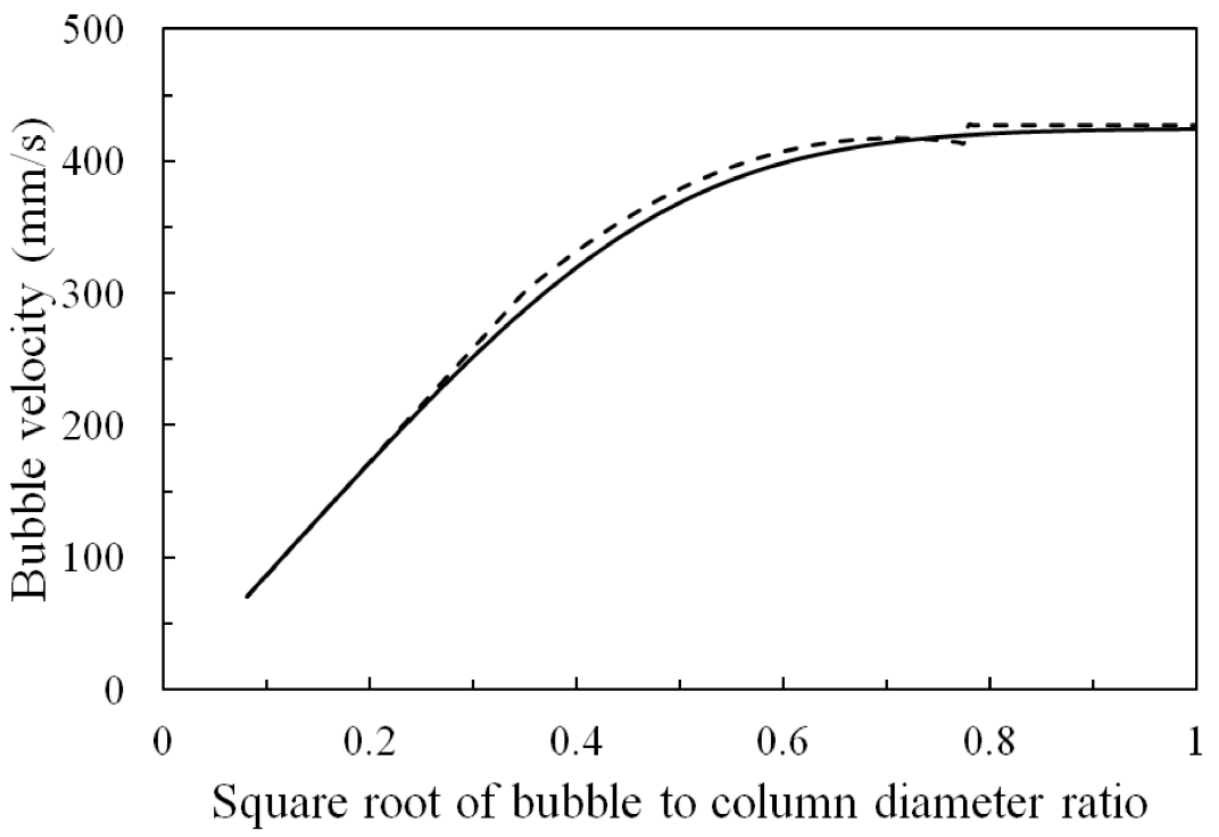


Fig. 2. Comparison of equation to describe wall effects. Collins[32]; -----Allahwala and Potter [33]

As originally proposed, $C_{0}=1.2$ but it was noted that this parameter took higher values as the Reynolds number, Re, decreased [37]. Subsequently [38], this has been quantified as

$C_{0}=\frac{2.27}{1+\left(\frac{R e}{4000}\right)^{2}}+\frac{1.2}{1+\frac{4000^{2}}{R e}}$

Many studies of bubble columns have used water as the liquid but in reality the physical properties of liquids employed in bubble column reactors can differ significantly from those of water. In particular, the ionic liquids considered here have viscosities considerably higher than that of water. A number of studies have looked at the effect of liquid viscosity during the bubbling of gas through a column of liquid [39]-[41]. These show that the gas hold-up, at a given gas velocity, decreases with increasing viscosity. Moreover for larger diameter column, the transition between homogeneous and heterogeneous flow was shifted to lower gas velocities with increasing liquid viscosity.

To predict the gas hold-up in bubble columns, Krishna et al. [42] have proposed an empirical correlation based on the concept that beyond the homogeneous/heterogeneous boundary any extra gas goes into the larger bubbles. They presented equations for the gas velocity and gas hold-up at the transition and also for the large bubble gas hold-up. Reasonable agreement is achieved over wide ranges of parameters.

There is a body of publications on the specific interfacial area such as the early work of Akita and Yoshida [19]. More recent work has used photography [23]-[25][44]-[47], nonisokinetic withdrawal in conjunction with electro-optic detection [48], two needle local probes [49], four fibre optic probes [50] and a Wire Mesh Sensor [21]. The liquids used were almost 
exclusively water with different chemical dissolved in them, e.g., $\mathrm{Na}_{2} \mathrm{CO}_{3}, \mathrm{NaHCO}_{3}, \mathrm{NaOH}$ [43], DEA [44], TEA [45], polymer plus surfactant [46] and surfactant [47]. However, the data on the effect of liquid viscosity are limited. The liquid viscosity investigated in [23] is up to 0.02 Pa s. The Wire Mesh Sensor was also employed to study the bubble behaviour of silicone oil (properties given in Table 1) [51]

The objective of this study is to show that a liquid, an aqueous solution of glycerol/potassium chloride whose physical properties are similar to the ionic liquid, e.g., $[\mathrm{EMIM}]\left[\mathrm{EtSO}_{4}\right]$, can determine the hydrodynamic properties of the ionic liquid and yet be much cheaper to purchase than the ionic liquid. The bubble velocity/size as predicted by the equation of Lin [29] show good agreement between the ionic liquid and a proposed modelling liquid. In this paper we will show that a similar agreement is present for the characteristics of Taylor bubbles and liquid slug and also specific interfacial area. The final section considers the present results together with those from selected published experiments with the aim of explaining the present results

\section{Experimental arrangements}

A vertical, acrylic resin column with an internal diameter of $38 \mathrm{~mm}$ and height of $800 \mathrm{~mm}$ was employed for the experiments reported here. Air was fed in through a porous, glass-sinter sparger (pore index 40-100 $\mu \mathrm{m}$, Grade 2) with a diameter 30mm. A square box, manufactured from acrylic resin sheet, was mounted around the column at a location $460 \mathrm{~mm}$ from the air sinter. It was filled with water and was intended to lessen the distortion due to the curved wall of the column. It was worthwhile to mention that the distortion can be further reduced by using a liquid with similar refractive index to acrylic rather than water to fill the box.

The gas flow rate was metered by trapping the air emerging for a fixed time period in an inverted cylinder which had originally been filled with water. Timing the volume of water in 
the inverted cylinder displaced by the gas allows the calculation of the gas flow rate. Measurements were repeated three times and only those cases where the results were reproducible were used.

Video images were obtained using a Phantom V7 Camera manufactured by Vision Research Inc.. This was employed with diffuse backlighting. Videos were taken at $1000 \mathrm{~Hz}$ for 5 seconds. The maximum resolution of the image is $800 x 600$ pixels.

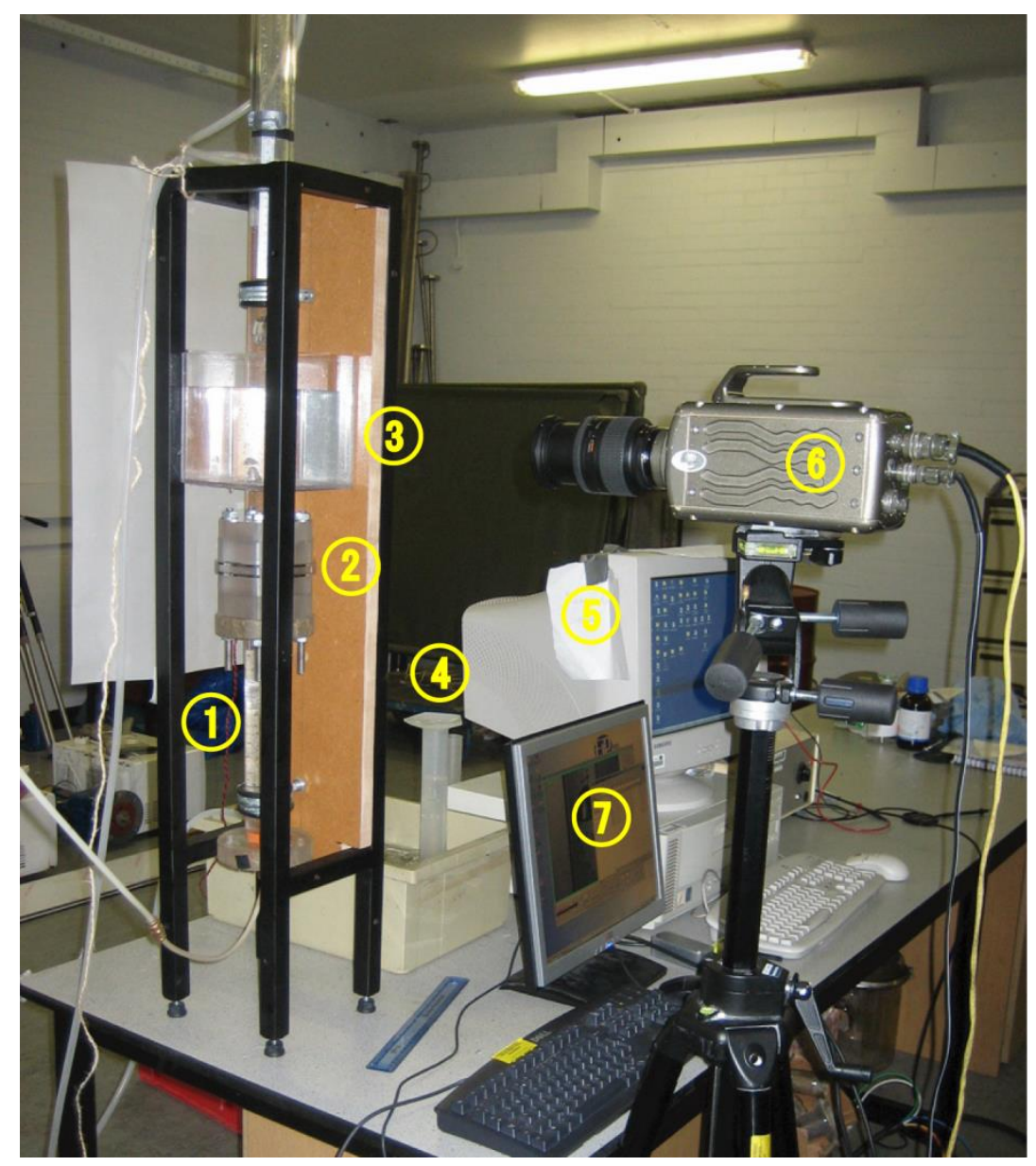

Fig. 3 Photograph of experimental arrangement. 1. Test section; 2. Conductance probe; 3. Window for visualization; 4. Inversed cylinder for gas flow rate measurement; 5. Computer for conductance probe; 6 . High speed camera; 7. Computer for high speed camera 
The measurement technique used to determine the fraction of the cross-section of the column occupied by gas follows the approach developed by, amongst others, Fossa [52] and depends on the difference in electrical conductivity (inverse of resistance) of the gas and the liquid. That of the gas is infinitely low whilst that of the liquid is (or can be made to be) of a more finite value. The conductivity is measured between two metallic rings mounted flush with the column wall. They are manufactured by placing two metal plates between three plates of acrylic resin and machining out a cylinder of the diameter of the column through them. The probe is characterized by the thickness of the rings, $s$, and the spacing between them, $D_{e}$. In this $D_{c}$ is the column diameter. For the probe employed in the present work the dimensions of $D_{e} / D_{c}$ and $s / D_{c}$ were 0.357 and 0.075 , respectively. It was positioned $350 \mathrm{~mm}$ above the sparger and provided with a $20 \mathrm{kHz},-1$ to +1 volt peak to peak alternating current, applied diagonally across the Wheatstone bridge. An instrumentation amplifier, a full wave rectifier and a band pass filter were installed before the signal was sent to the data acquisition board. This gives the time resolved gas hold-up for a system where the gas hold-up varies with time. Mean gas hold-up is given by integrating the time varying signal.

The conductivity of a liquid depends on temperature as well as on chemical species/concentration. The temperature effect was dealt with by running the calibrations and measurement on the same laboratory which was essentially at a constant temperature for all the work. However, to eliminate the minor variations due to temperature effect a measurement was made at the start of each run with the column full of liquid. All conductivities were nondimensionalised with this value.

The relationship between the dimensionless conductivity and gas hold-up was obtained by three forms of careful calibration. In the first, inserting strings of $6 \mathrm{~mm}$ plastic beads, whose electrical resistance is very small and similar to that of air. A second method was to supply air to the test section at a very low flow rate. The gas hold-up was determined from the swell of 
the two phase mixture above the liquid only height. A third approach took photos of Taylor bubble and from image analysis determined the gas hold-up.

Taking the ratio of output of two-phase in the sensor relative to the output for that on liquid only, the dimensionless conductance $G e^{*}$, gas hold-up can be calculated by using following fourth order polynomial equations based on the calibration results shown in Fig. 4:

$\varepsilon_{g}=2.127 G e^{* 4}-5.063 G e^{* 3}+2.878 G e^{* 2}-0.9446 G e^{*}+1.002 \quad$ for ionic liquid

$\varepsilon_{g}=1.053 G e^{* 4}-3.158 G e^{* 3}+1.829 G e^{* 2}-0.7217 G e^{*}+0.9987$ for aqueous glycerol

$\varepsilon_{g}=1.764 G e^{* 4}-3.645 G e^{* 3}+1.535 G e^{* 2}-0.6530 G e^{*}+0.9991$ for water

Details are given by Kaji et al.[9].

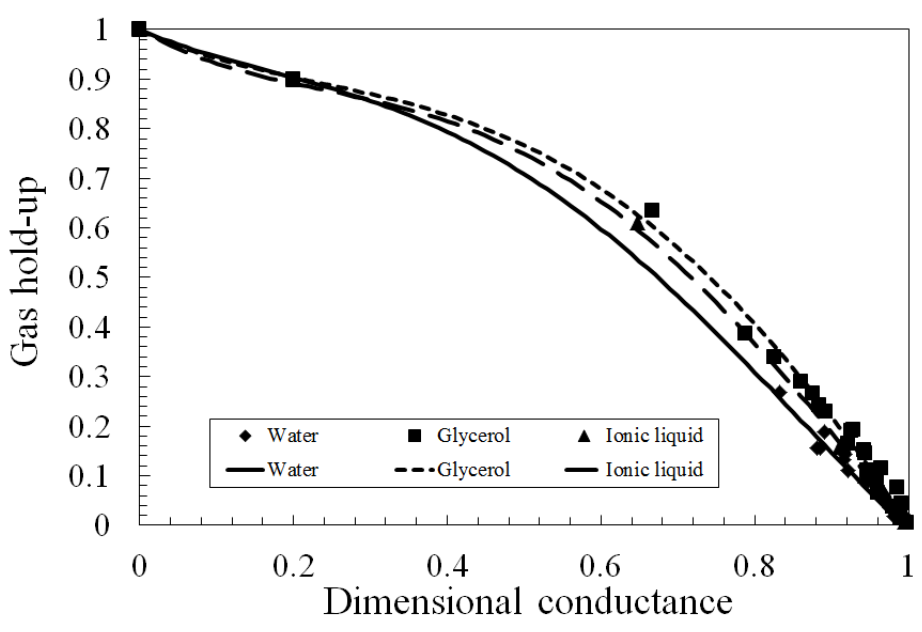

Fig. 4 Calibrations curves for all three liquids

Three liquids were used in this study; water, ionic liquid (1-Ethyl-3-methylimidazolium ethylsulphate, [EMIM][EtSO4]) and an aqueous solution of glycerol (83.7\%) and potassium chloride $(1.3 \%)$. This last had a viscosity similar to [EMIM][EtSO4], which is about hundred times that of water. The salt was added to ensure that the conductivity was sufficiently high so that the conductance sensor could be employed. The physical properties of all liquids at $20^{\circ} \mathrm{C}$ are tabulated in Table 1. The viscosities and conductivities were measured using a Brookfield viscometer and WTW KF 340 conductivity meter respectively. The viscosity of water and 
surface tensions were obtained from physical property tables. The other properties of [EMIM][EtSO4] were taken from Gomez et al. [53].

\section{Table 1}

Physical properties of liquids used in the present experiments and in comparisons

\begin{tabular}{|l|l|l|l|l|l|}
\hline & Liquid & $\begin{array}{l}\text { Density } \\
\left(\mathrm{kg} / \mathrm{m}^{3}\right)\end{array}$ & $\begin{array}{l}\text { Viscosity } \\
(\mathrm{Pa} \mathrm{s})\end{array}$ & $\begin{array}{l}\text { Surface } \\
\text { tension } \\
(\mathrm{N} / \mathrm{m})\end{array}$ & $\begin{array}{l}\text { Kapitza } \\
\text { number }\end{array}$ \\
\hline $\mathrm{A}$ & Water & 1000 & 0.001 & 0.073 & 0.0022 \\
\hline B & {$[$ EMIM][EtSO 4$]$} & 1241 & 0.12 & 0.047 & 0.35 \\
\hline $\mathrm{C}$ & $\begin{array}{l}\text { Aqueous glycerol } \\
\text { solution with 13\% } \\
\text { potassium chloride }\end{array}$ & 1224 & 0.108 & 0.062 & 0.26 \\
\hline D & Silicone oil & 900 & 0.005 & 0.02 & 0.032 \\
\hline E & Glucose & 1380 & 0.55 & 0.076 & 1.1 \\
\hline
\end{tabular}

The Kapitza numberwhich has the form of $\mu\left(\mathrm{g} / \rho \sigma^{3}\right)^{0.25}$ it is the Morton number raised to the quarter power. It is seen that the liquids listed in Table 1 cover three decades.

\section{Results and Discussion}

Measurements on water and viscous liquids

Fig. 5 Video stills and one second of gas holdup time trace for water, [EMIM][EtSO4] and aqueous solution of glycerol/potassium chloride at gas superficial verlocities of 3,15 , 35 , and $\mathrm{mm} / \mathrm{s}$

A frame of high speed camera and time series

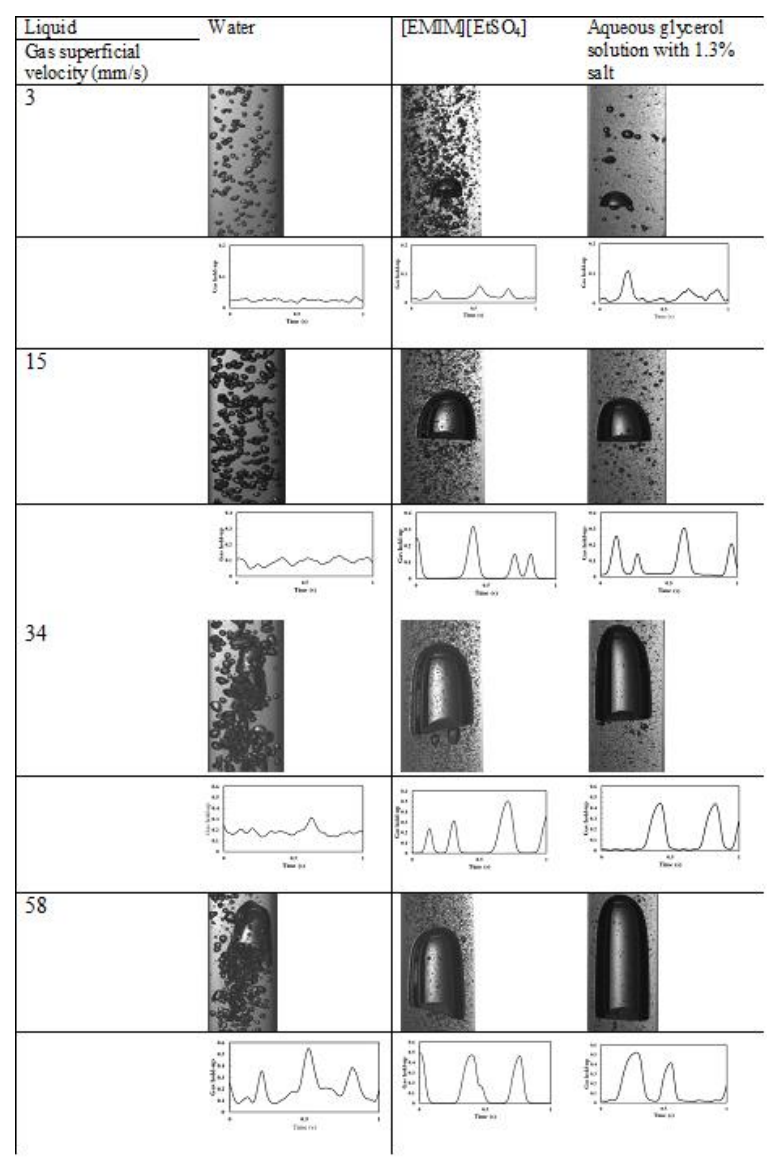
of cross-sectionally average gas hold-up obtained from different fluids at four constant gas flowrates are summarised in Fig. 5. For viscous fluid, the experiment was run at the required gas flow for at least half an hour to 
stabilise the flow before data were taken. The results were taken at four different inlet gas flowrates; $3,15,35$ and $58 \mathrm{~mm} / \mathrm{s}$. In the figure, images chosen from the sequence are the frame which periodic large bubbles can be observed. For time series of gas hold-up, data of 1 second out of the 60 seconds recorded are presented for illustration. In the top row, at lowest gas flowrates, the distinctive difference can be easily identified from the image between different liquids. In this condition, cap bubbles are observed for ionic liquid, and aqueous glycerol with potassium chloride, whilst typical bubbly flow is seen for the case of water. In the time series of gas hold-up, that for bubbly flow shows small amplitude variation, indicative that the bubble concentration is not uniform. For the two more viscous liquids, although spherical cap bubbles are commonly observed, the portion of the concentration of smaller bubbles is different. When bubble sizes categorized roughly into three (nominally $10 \mathrm{~mm}, 3 \mathrm{~mm}$ and $0.1 \mathrm{~mm}$ ), the smallestsize of bubble for ionic liquid and aqueous glycerol with potassium chloride is more concentrated than aqueous glycerol. Also the middle-sized bubble concentration is higher as following order: ionic liquid $>$ aqueous glycerol with Potassium chloride. When the gas flowrate increases to $15 \mathrm{~mm} / \mathrm{s}$, the second row, it is observed from the images that the size of cap bubbles and bubble sizes for water increases. If there is a further increase of the gas flowrate, the spherical cap bubbles become Taylor bubbles. In the times series of gas hold-up the Taylor bubbles are characterised by large peaks. The number of middle-sized bubble becomes less and small bubbles are still rather few for this condition. For water, the flow pattern becomes transient between bubbly and slug flow. For the highest gas flowrate 
examined, the bubbles become larger for ionic liquid and aqueous glycerol. The flow pattern for water is closer to slug flow.

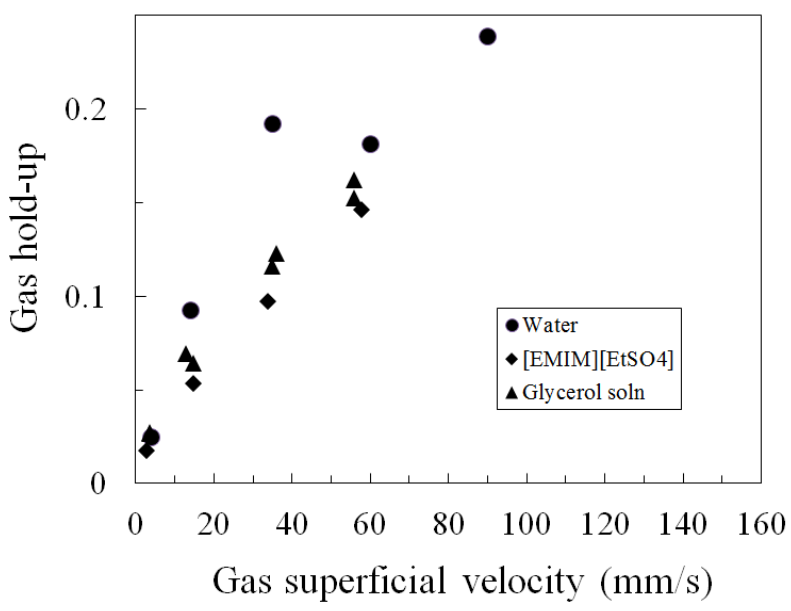

Fig. 6. Time averaged gas hold-up for air flowing through water, [EMIM] $\left[\mathrm{EtSO}_{4}\right]$ and aqueous glycerol with $1.3 \%$ potassium chloride.

Data of time averaged gas hold-up are given in Fig. 6 for the ionic liquid [EMIM][EtSO4] as well as an aqueous glycerol/potassium chloride solution. It is noted that these gas hold-up values are distinctly lower than those for water in spite of the gas distributor having similar sized small holes to those used in the data shown in Fig. 6. As can be seen in Fig. 6, the gas hold-up data for water first increases, then decreases and then increases again. It the conventional bubble column literature, the first region with a positive gradient is termed homogeneous flow - steady streams of small bubbles. The second region with positive gradient is known as heterogeneous (or churn-turbulent) flow. The part in between is termed transitional flow. The other two liquids have lower gas hold-up values than water and the flow is taken as heterogeneous. The accuracy of the data can be determined from the reproducibility where experiments have been repeated at the same gas flow rate. The uncertainty can be identified as $-3.3 \% /+2.5 \%$. The frequency of the Taylor bubbles falls from $2.5 \mathrm{~Hz}$ to $2 \mathrm{~Hz}$ as the gas velocity increases whilst the amplitude goes from 0.4 to 0.49 with increasing gas flow rate. 
As discussed in the Introduction, the coalescence of the large bubbles is an important aspect of these flows. This phenomenon can be clearly observed from the videos taken using a high speed camera. Fig. 7 shows a sequence of stills illustrating an example of two Taylor bubbles coalescing in aqueous glycerol/potassium chloride solution with a gas superficial velocity of $35 \mathrm{~mm} / \mathrm{s}$. In contrast with the equivalent large bubbles in water, shown in Fig. 5, these bubbles have a smooth shape. However, the most obvious feature of these images is the distortion of the trailing bubble. Less obvious is the difference in the velocity of the leading and trailing bubbles. It is much clearer when the position/time information of the noses and tails of the bubbles is examined as in Fig. 8. This shows how the velocity (the slope of the position/time plot) of the trailing bubble is significantly larger than that of the leading one.

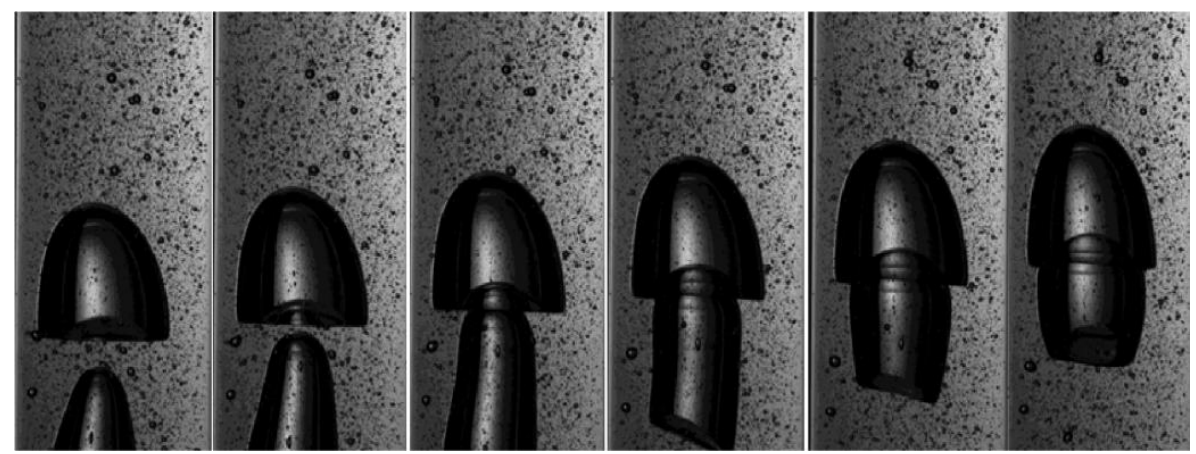

Fig. 7. Stills illustrating coalescence of two succeeding bubbles - air passing through aqueous glycerol solution containing $1.3 \%$ potassium chloride. Gas superficial velocity $=35$ $\mathrm{mm} / \mathrm{s}$

Fig. 8. Axial positions of noses and tails of bubbles shown in Fig. 7

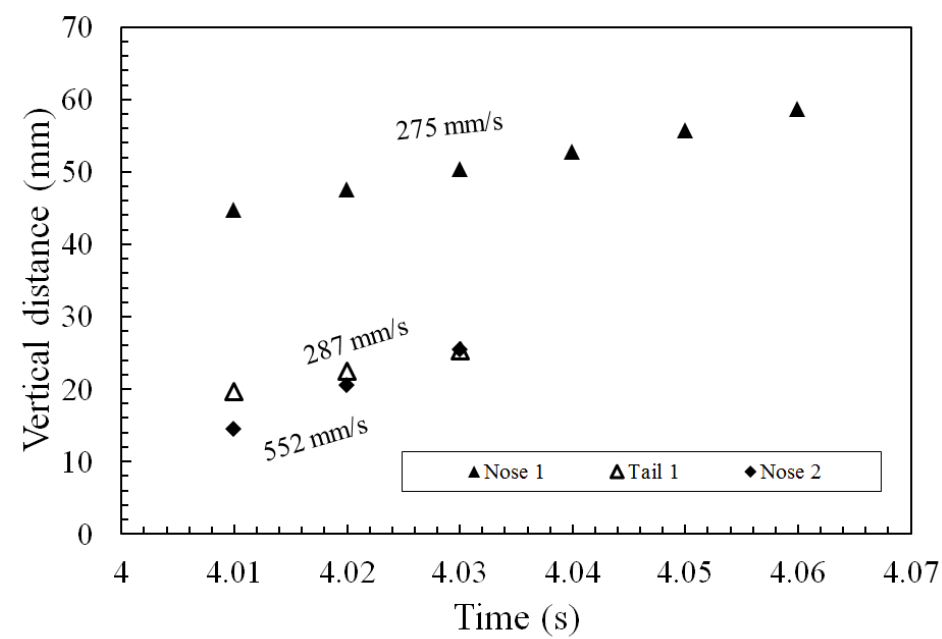
coalescence between three Taylor 
bubbles. Here, in particular, the distortion of the third bubble is very marked. This distortion is probably caused by the wake behind the preceding bubble. The difference between the velocities of the bubbles is clearly illustrated in the position/time plot.
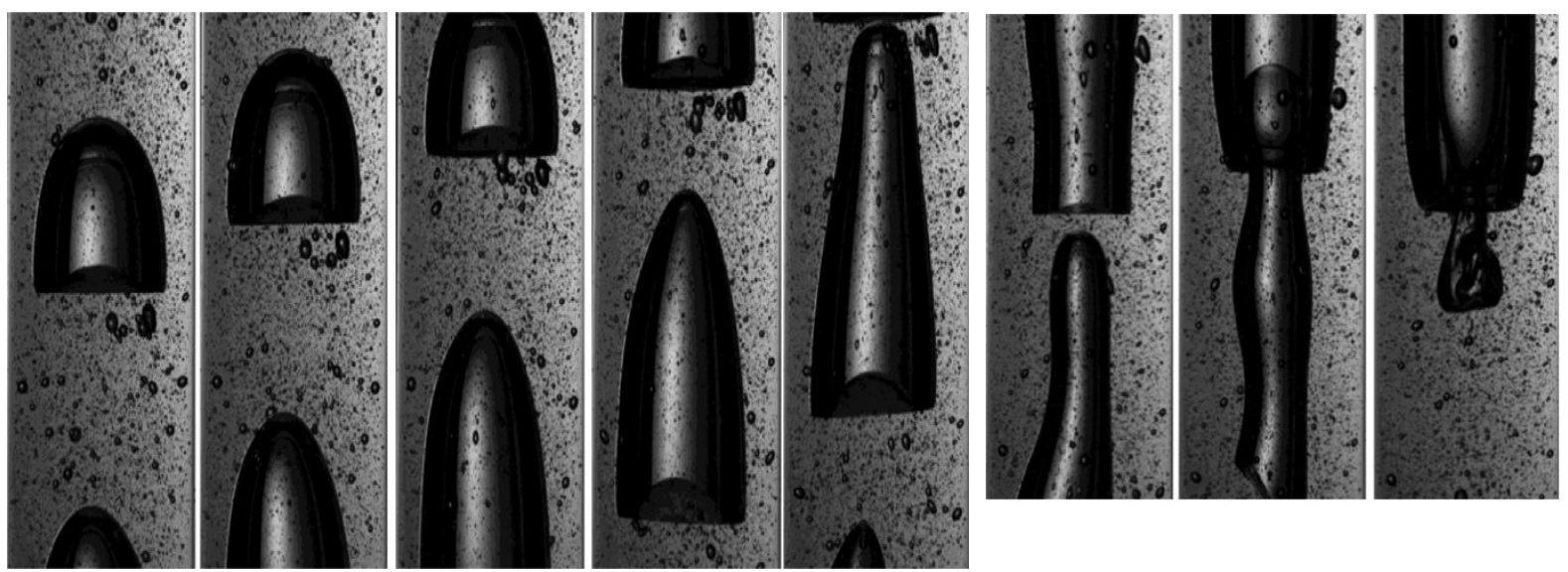

Fig. 9. Stills illustrating coalescence of first two bubbles, part of a coalescence of three bubbles. Air passing though aqueous glycerol solution containing 1.3\% potassium chloride. Gas superficial velocity $=35 \mathrm{~mm} / \mathrm{s}$

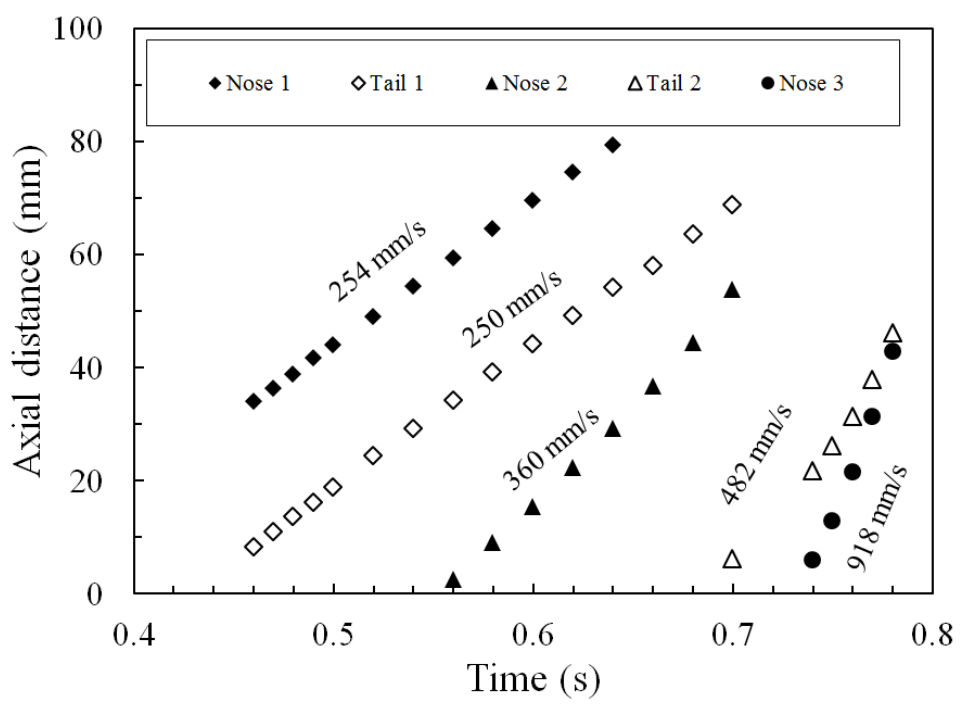

Fig. 10. Axial positions of noses and tails of bubbles shown in Fig.9

A detail of some importance is seen in Fig. 9. This is presented in magnified form in Fig. 11. The third bubble has penetrated the combined product of the first coalescence a distance of $\sim 22$ $\mathrm{mm}$ yet it can be seen that there still exists a continuous liquid film between them. Because of 
the high viscosity of the liquid, the film cannot drain very fast and a finite time is required for sufficient thinning to occur before rupture can take place. It is noted that this film is very thin and probably very good for mass transfer.

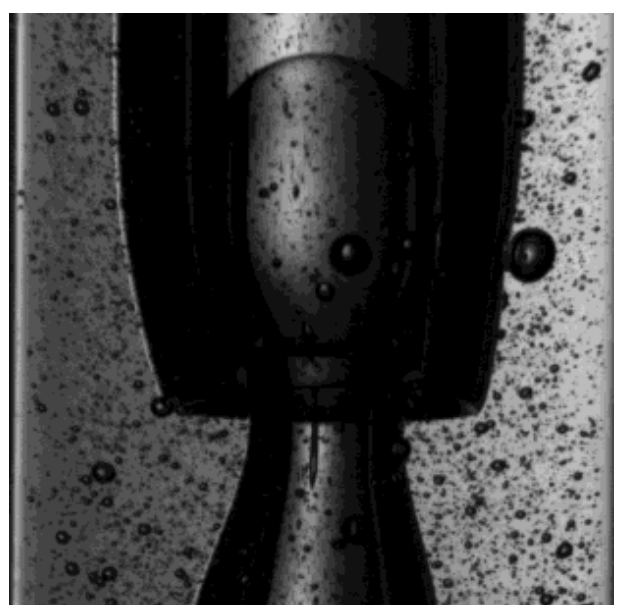

Fig. 11. Expanded view of the two bubbles shown in Fig. 9 and illustrating a bubble within a bubble with an as yet unbroken film of liquid between them

In this part of the analysis the focus is concentrated on Taylor bubbles consequently all bubbles are essentially the same shape. The velocities from these coalescing bubbles as well as bubbles which do not coalesce within the field of vision are shown in Fig. 12. The arrows mark bubbles which have coalesced just as they are coming into the field of view. In this small sample, $45 \%$ bubbles have undergone coalescence. The figure shows clearly that most bubbles, isolated ones as well as the leading bubbles of a coalescing set, have essentially the same velocity. The larger velocities and, indeed, acceleration of trailing bubbles is very evident. The line labelled model is based on Eqs. (6) and (7) using Fr from the methods of Viana et al. [36], for this liquid $\mathrm{Ar}=\rho_{L}^{2} g D_{L}^{3} / \mu_{L}^{2}=69140$, i.e., $>10000$, and so $\mathrm{Fr}=0.35$

Fig. 12. Velocities of sequential Taylor bubbles. Arrows identify bubbles which had undergone a coalescence event. 


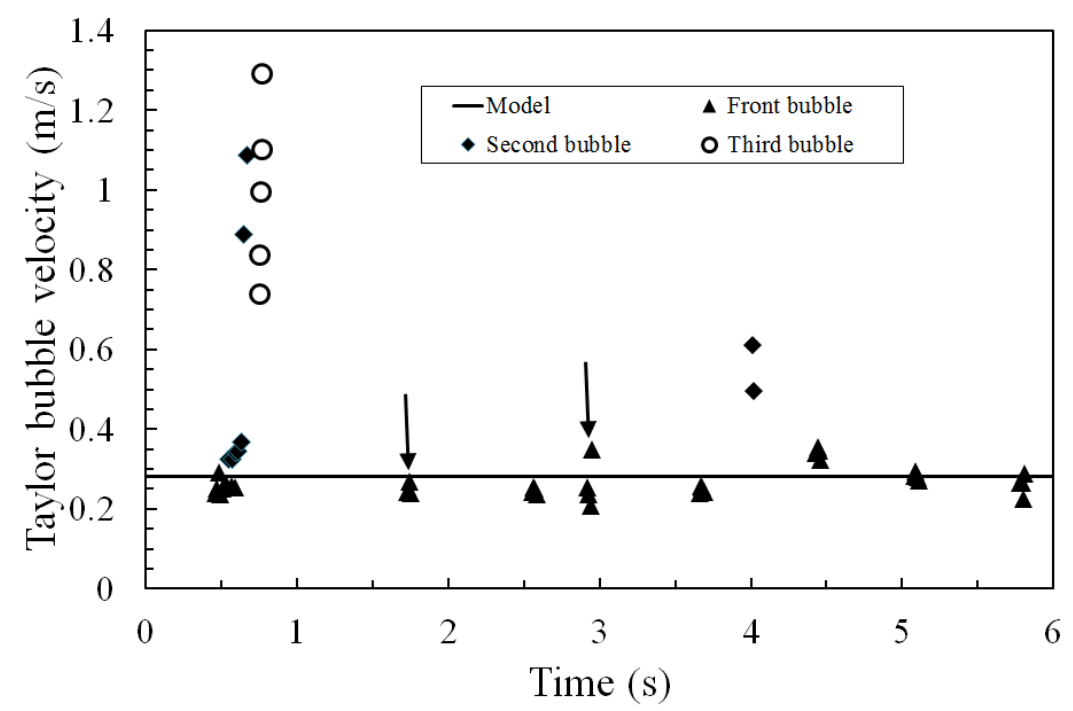

From the videos presented in Fig. 5, lengths of individual Taylor bubbles extracted from the video sequences by using an appropriate scale. This is shown in the form of a Probability Density Function. For the same flow conditions, the time series of gas hold-up can be converted to axial distances. From this, the length of large bubbles and liquid slug can be exctracted. The conversion to axial distances is achieved by multiplying time by the velocities of large bubbles obtained from Eq. (6) and (7) with Fr determined using the method of Viana et al. [36]. Fig. 13 shows the Probability Density Functions for Taylor bubbles and liquid slugs for the aqueous solution of glycerol and potassium chloride at a gas superficial velocity of 35 $\mathrm{mm} / \mathrm{s}$. There is reasonable agreement between the data from the two sources, particularly if it is remembered that the video data was obtained for a shorter time ( 5 seconds) than that from the conductance time traces (60 seconds) and consequently, small samples, 8 for the video and 150 for the time series. Statistics of the lengths were extracted for both the aqueous solution of glycerol and potassium chloride and the ionic liquid [EMIM][EtSO4]. Means and standard deviations for the Taylor bubbles and liquid slugs are presented in Figs. 14 and 15 respectively. Both means and standard deviations increase with increasing gas superficial velocity. There is a small difference between the data from the two liquids, probably caused by the small difference in physical properties. In Fig. 14, the lengths are labelled as those for large bubbles 
as the smallest lengths are only $\sim 0.5$ of the column diameter. Clearly these are spherical cap bubbles whilst the larger ones can be labelled as Taylor bubbles. However, it is recognised that this distinction is semantic because, as illustrated in Fig. 2, the drift velocity part of the bubble velocities will be the same.

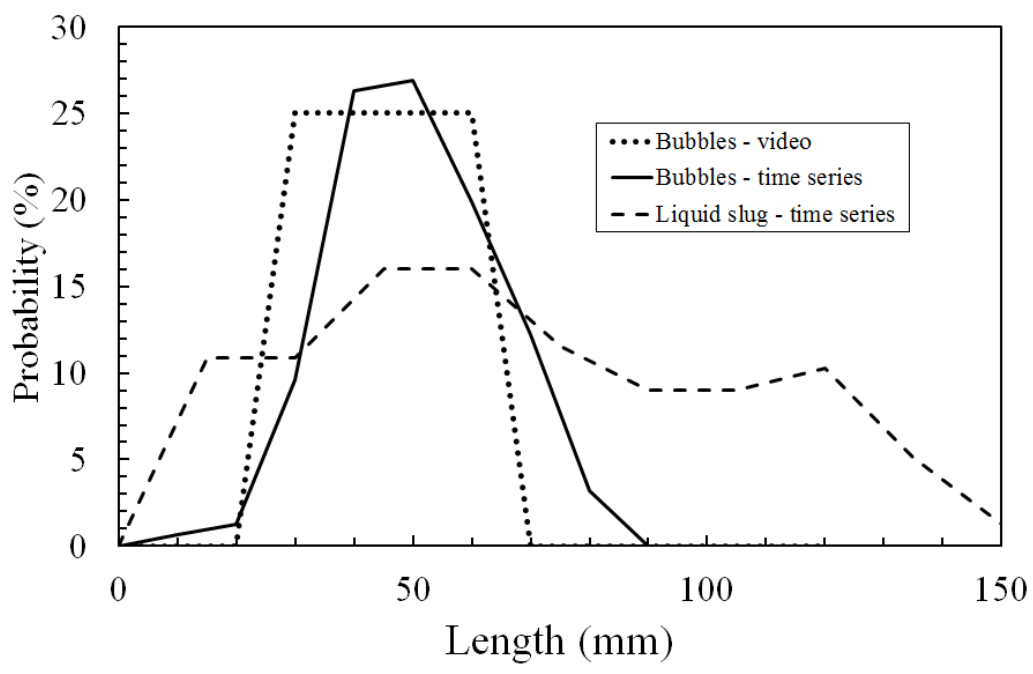

Fig. 13. Probability Density Function of lengths of large bubble and of liquid slugs

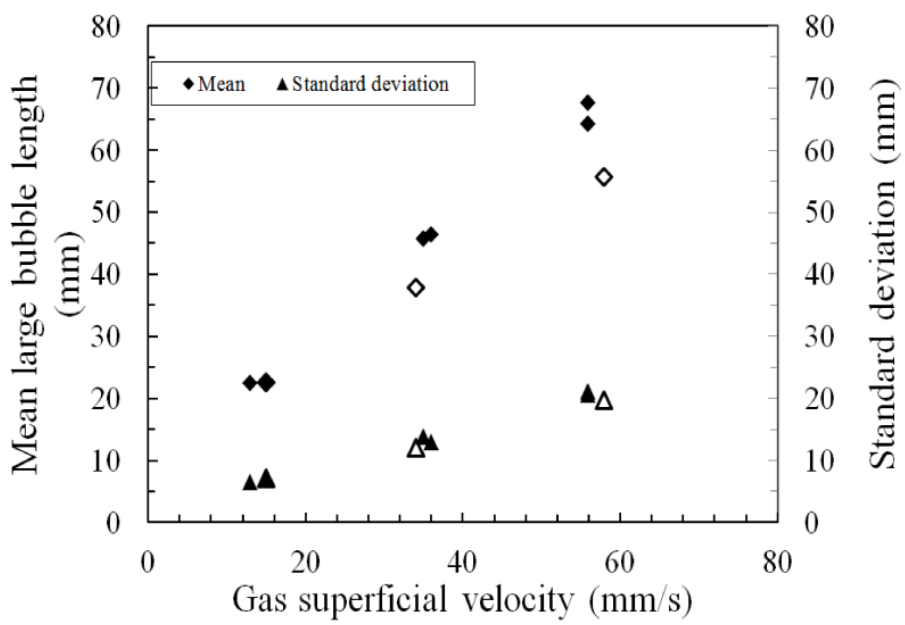

Fig. 14. Mean and standard deviations of large bubbles. Closed symbols - aqueous glycerol/potassium chloride solution; open symbol - [EMIM][EtSO $\left.{ }_{4}\right]$

Fig. 15. Mean and standard deviations of liquid slugs. Closed symbols - aqueous glycerol/potassium chloride solution; open symbol - [EMIM][EtSO 4 


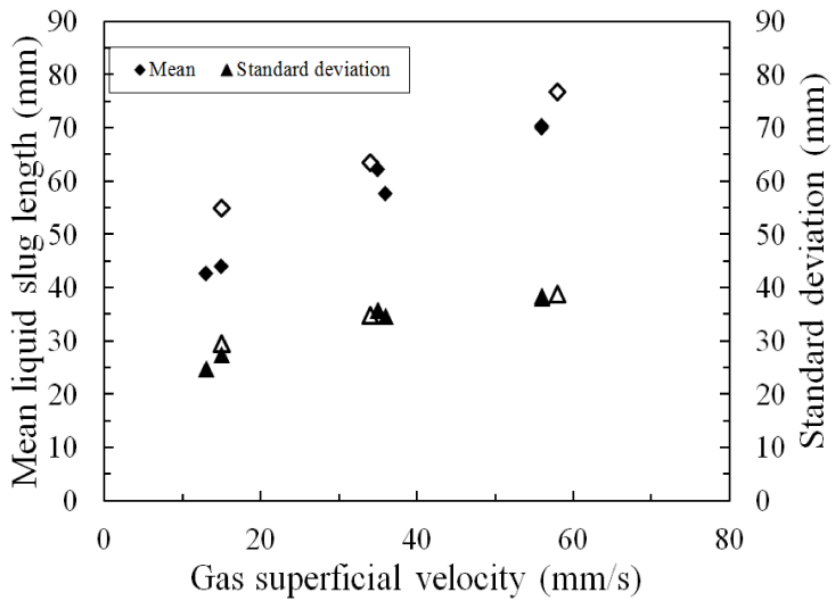

If the literature of bubble coalescence is examined, there are a number of papers on bubble coalescence, e.g., [59][60]. These address the coalescence of bubbles at a single orifice. The models give an excellent picture of this specific process. In contrast, there is less material on the coalescence of Taylor bubbles. The main aspect that is studied is the merging of two sequential Taylor bubbles, an example is given in [61]. They show that the follower bubble accelerates into the tail of the leader once the inter-bubble distance is $\leq 5$ column diameters. The cause of this effect is the nose of the second bubble entering the wake of the first. Such behaviour for the present liquids is shown in Figs. 7 and 9. It is noted that the data does not extend to higher viscosities. Now, apart from the changes in the numbers of large bubbles, the coalescence process is important for the thin liquid membrane created between the bubbles and illustrated in Fig. 11. Such a thin film will contribute to the specific interfacial area. However, this has not yet been quantified.

\section{Bubble sizes and specific interfacial area}

An image processing method based on the combination of a Sobel filter and Hough transform is applied to obtain the diameter of bubbles. The applicability of Sobel filter to bubbly flow is described by Broder and Sommerfeld [54]. The approach was developed further [55-56] by using a normal line Hough transform. This has been successful applied to two cases, microbubbles and bubbles in rod bundles. The bubbles examined were less than $1 \mathrm{~mm}$ and 
much smaller than the depth of focus; therefore, overlapped bubbles need to be detected and separated by using normal line Hough transform.

Fig. 16 shows the examples of the image processing. In the figure, (a) is an original image taken from high speed camera, (b) is the image applying Sobel filter for edge detection, (c) is the image of a vote function after applying normal line Hough transform which is shown by gathering lines indicating the centre of bubbles and (d) is a result of diameter of bubbles detected. The method capable of detecting all bubbles present in the original image since no calibration and adjustment of lighting is carried out in beforehand. Using this approach, enough bubbles can be identified to distinguish flow characteristics for the present study.

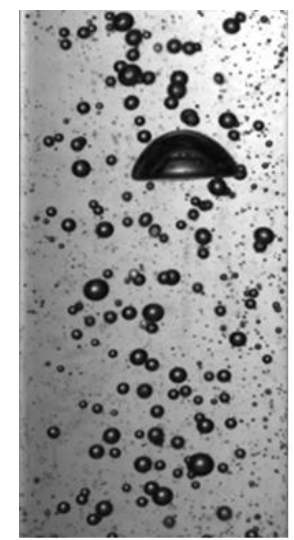

(a)

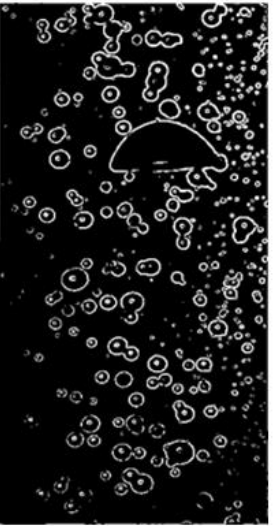

(b)

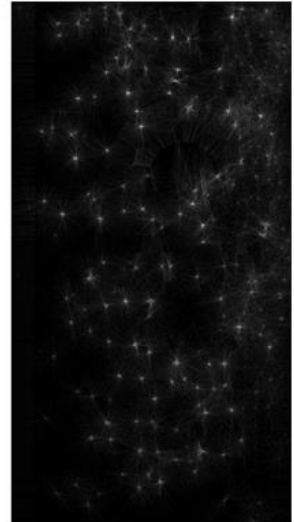

(c)

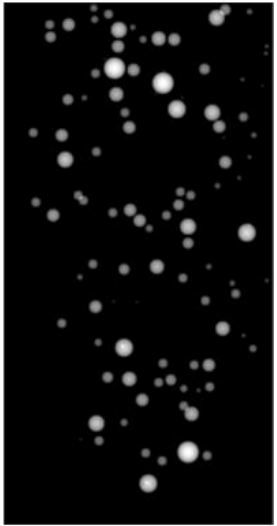

(d)

Fig. 16. Example of bubble diameter determination process. (a) original image; (b) image after applying Sobel filter for edge detection; (c) after applying line Hough transform; (d) resulting bubbles detected.

Analysis using the above approach were carried out on the runs at the lower flow rates of both the aqueous glycerol /potassium chloride solution and for [EMIM][EtSO $\left.\mathrm{E}_{4}\right]$. Sample sizes ranging from 31-502 were employed. The bubble sizes measured were seen to range from 1 to $15 \mathrm{~mm}$. The values of Sauter mean diameter obtained are given in Table 2.

Table 2

Sauter mean diameters measured and predicted by Eq. (4) 


\begin{tabular}{|l|l|l|l|}
\hline Liquid & $\begin{array}{l}\text { Gas superficial } \\
\text { velocity } \\
(\mathrm{mm} / \mathrm{s})\end{array}$ & $\begin{array}{l}\text { Measured Sauter mean } \\
\text { diameter }(\mathrm{mm})\end{array}$ & $\begin{array}{l}\text { Sauter } \\
\text { diameter predicted } \\
\text { using Eq. (4) }(\mathrm{mm})\end{array}$ \\
\hline \multirow{2}{*}{$\begin{array}{l}\text { Aqueous solution of } \\
\text { glycerol and potassium } \\
\text { chloride }\end{array}$} & 3.6 & 7.4 & 7.32 \\
\cline { 2 - 4 } & 15 & 7.6 & 11.9 \\
\hline [EMIM][EtSO $]$ & 35 & 7.7 & 15.9 \\
\cline { 2 - 4 } & 3 & 7.2 & 6.1 \\
\hline
\end{tabular}

The measured values of Sauter mean diameter have been compared with those predicted by the correlating equation [25] shown as Eq. (4) above. Though there good agreement at the lowest gas flow rate, the measured and calculated values diverge as the gas flow rate increases. This is because, in the present work, we are not including spherical cap bubbles. It is noted that as seen in Fig. 16, Fig. 6 of Zhang et al. [11] also shows spherical cap bubbles in photos from a position higher up the column. The bubble sizes reported [11] are in agreement with values predicted by Gaddis and Vogelpohl [28] which is the appropriate model for the geometry [11].

The values obtained from the gas hold-up and bubble sizes from the present work are plotted in Fig. 17 together with the data of Zhang et al. [11]. This data set was selected as it is the only other source of data from an ionic liquid. For the lowest gas flow rates of the present data the specific interfacial area is determined from Eq. (1), in all other cases Eq. (3) is employed. The contribution from the small bubbles in the liquid slug region is allowed for by using the specific interfacial area for the highest gas superficial velocity at which it was measured. As seen in

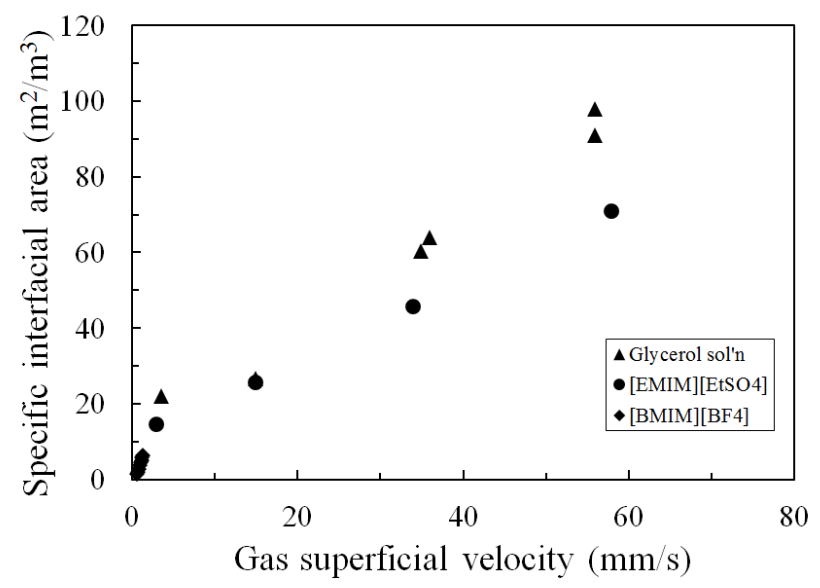


Table 2 there are only small variations in the value of Sauter mean diameter. Though they are from different ranges of gas superficial velocities, the present data and those of Zhang appear to lie on the same curve.

Fig. 17. Effect of gas superficial velocity on specific interfacial area. For [EMIM][EtSO 4 , aqueous solution of glycerol and potassium chloride and [BMIM][BF4]. This last is from Zhang et 1. [11].

Experiments [49] have been carried out using liquid with viscosities encompassing the ones used in the present work but from larger diameter bubble columns (160, $230 \mathrm{~mm}$ compared with the $38 \mathrm{~mm}$ column in the present work). However, only mean gas hold-up was measured. A qualitative report of the bubble sizes present was also provided though this just reported as large and small bubbles.

\section{Other (lower viscosity)}

Apart from the work of Zhang et al. [11] and the work presented here, there are no published data on specific interfacial area for liquids of viscosities similar to those used here. It was thought useful, to place the work in context, to examine the data from five sets of experiments. The geometric details and physical properties of the liquids employed are tabulated in Table 3 together with the methods of measurement employed. Two of them $[48,50]$ used water, the third [57] employed cyclohexane, a liquid with a surface tension much smaller than water and the fourth [51] used a silicone oil which has a low surface tension and a viscosity of 5 times that of water. These four are all from columns of diameter $>100 \mathrm{~mm}$ and had distributors which were perforated plates with holes of small diameter, $0.5 \mathrm{~mm}[49,50,52,57]$. The fifth employed water and had a gas distributor with larger holes in a smaller diameter column, 67 $\mathrm{mm}$, and give results in the slug flow regime [58]. Before considering the specific interfacial 
area, it is instructive to examine how the gas hold-up varies with gas superficial velocity for these data. Fig. 18 shows the values that were obtained. The first thing to be noted is that two of the sources have gas hold-up information obtained by more than one technique. Those labelled level swell provide global gas hold-up values determined from the height of the expanded, aerated liquid column. It can be seen that local values obtained from other techniques are close to the level swell data, maximum deviation $\sim 12.5 \%$. All the data lie in a band with little variations due to column diameter, flow regime or gas distributor as expected from published information.

For four of the data sets examined in Fig. 19, the sources also measured bubble sizes and so specific interfacial area was obtained via Eq. (1) $[49,50,51,57]$. For the remaining data set which presented slug flow information, the paper [58] provides all the necessary information, i.e., the diameters and the lengths of the Taylor bubble and the lengths of the liquid slug, which can be used in Eq (3). These experiments were for air-water in a $67 \mathrm{~mm}$ diameter column $6 \mathrm{~m}$ tall with measurements made at the $5 \mathrm{~m}$ position. The values of specific interfacial area obtained are shown in Fig. 19 which shows a factor of nearly 5 between the different data sets. It is noted that the data in [50] were presented as the radial profiles of local values. Overall values were calculated by integration of these. In contrast, the silicone oil work [51], has values of specific interfacial area which is nearly an order of magnitude lower. Given the similarity between the values of gas hold-up between all the data sets, it is obvious that these lower values of specific interfacial area must be caused by larger bubble sizes. It is known [28] that bubble sizes increase with increasing viscosity. For this particular liquid bubble sizes have been measured. Examples of the distribution of sizes are shown in Fig. 20 for the lowest and highest gas superficial velocities studied. The vertical lines are the bubble diameter predicted from the equation of Gaddis and Vogelpohl [28] which is reasonably close to the main peak of each 
distribution. These sizes are those created at the distributor, the larger bubbles present are from the process of coalescence.

The highest specific interfacial area values [49] occur because it has small diameter orifices but also a high percentage open area (a large number of orifices per unit cross-sectional area of column. This makes for a lower flow rate per orifice and consequently smaller bubbles. That together with a lower level of coalescence makes it an effective generator of large interfacial area.

When the data from the present work, shown in Fig. 17, is compared to the values for the other data sets shown in Fig. 19, it is seen that the present values are about the same as that for the data set which operated in slug flow. This confirms that it is slug flow that encourages low values of specific interfacial area and more viscous liquids are more likely to be in slug flow.

Table 3

Geometry and physical properties for data discussed in section 4.5

\begin{tabular}{|l|l|l|l|l|l|l|l|}
\hline Source & $\begin{array}{l}\text { Column } \\
\text { diameter } \\
(\mathrm{mm})\end{array}$ & $\begin{array}{l}\text { Orifice } \\
\text { diameter } \\
(\mathrm{mm})\end{array}$ & $\begin{array}{l}\text { Open } \\
\text { area } \\
(\%)\end{array}$ & $\begin{array}{l}\text { Density } \\
\left(\mathrm{kg} / \mathrm{m}^{3}\right)\end{array}$ & $\begin{array}{l}\text { Viscosity } \\
(\mathrm{Pa} \mathrm{s})\end{array}$ & $\begin{array}{l}\text { Surface } \\
\text { tension } \\
(\mathrm{N} / \mathrm{m})\end{array}$ & $\begin{array}{l}\text { Method of } \\
\text { measurement }\end{array}$ \\
\hline$[49]$ & 390 & 0.5 & 2.2 & 1000 & 0.001 & 0.073 & $\begin{array}{l}\text { Level swell, } \\
\text { double needle } \\
\text { probe }\end{array}$ \\
\hline$[50]$ & 162 & 0.5 & 0.15 & 1000 & 0.001 & 0.073 & $\begin{array}{l}\text { Level swell, CT, } \\
\text { four-point optical } \\
\text { probes }\end{array}$ \\
\hline$[51]$ & 127 & 0.5 & 0.19 & 900 & 0.005 & 0.02 & $\begin{array}{l}\text { Level swell, } \\
\text { WMS }\end{array}$ \\
\hline$[60]$ & 200 & 0.5 & 0.8 & 789 & 0.00089 & 0.025 & $\begin{array}{l}\text { Pressure } \\
\text { difference } \\
\text { Double needle } \\
\text { probe }\end{array}$ \\
\hline$[61]$ & 67 & 6 & & & & & \\
\hline
\end{tabular}




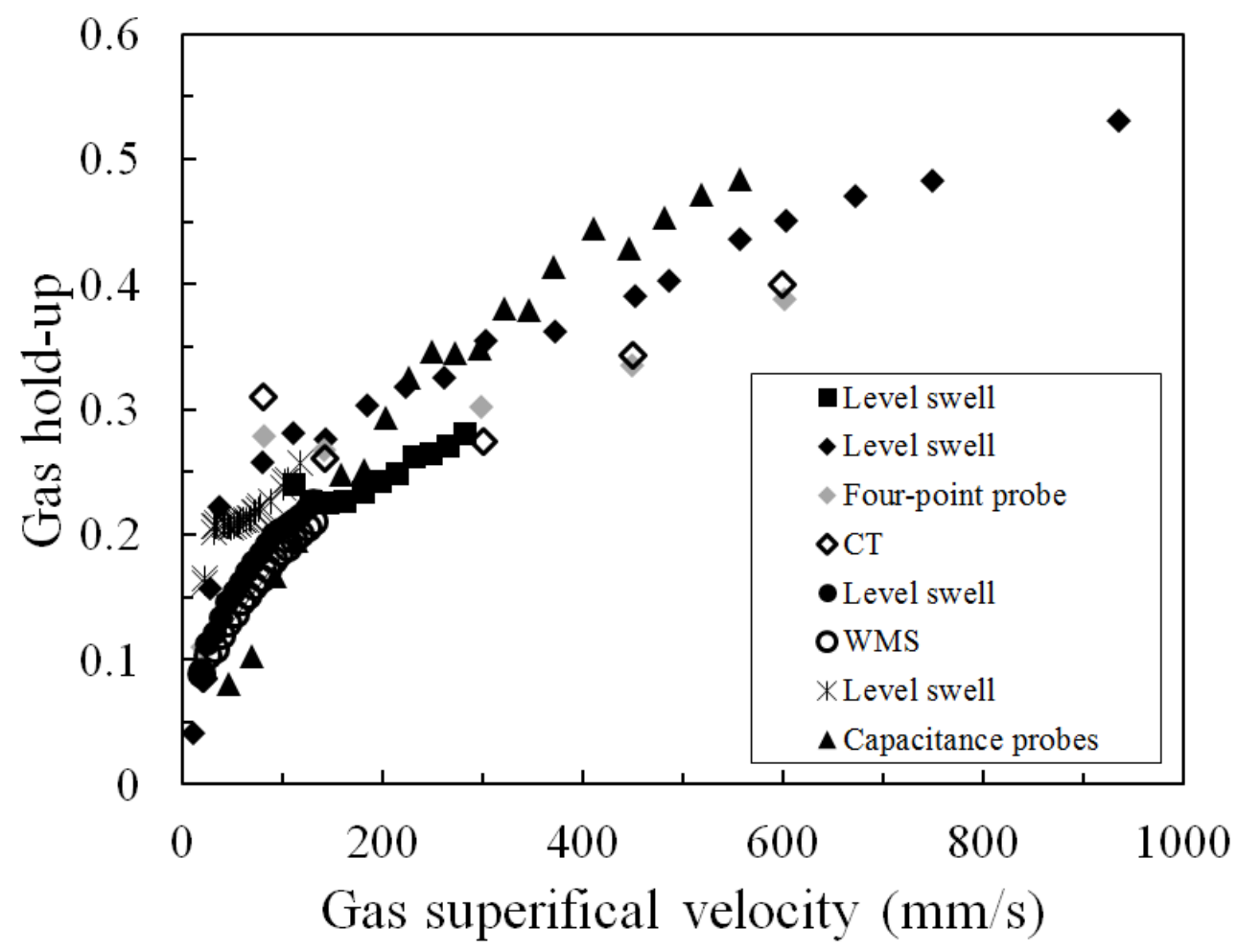

Fig. 18 Effect of gas superficial velocity on gas hold-up from sources in Table 3. [ [49]; $\diamond \diamond[50] ; \bullet$ o [51]; * [60]; $\Delta[61]$.

Fig. 19. Specific interfacial area from literature sources for air-water, cyclohexane and airsilicone oil. \ $67 \mathrm{~mm}$ diameter column [61 air-water determined using Eq. (3); ( $390 \mathrm{~mm}$ diameter column [49], air-water determined using Eq. (1); $162 \mathrm{~mm}$ diameter column [50], air-water determined using Eq. (1). * $200 \mathrm{~mm}$ diameter column [60], air cyclohexane deermined using Eq. (1). • 127 mm diameter column [51] air-silicone oil determined Eq.(3)

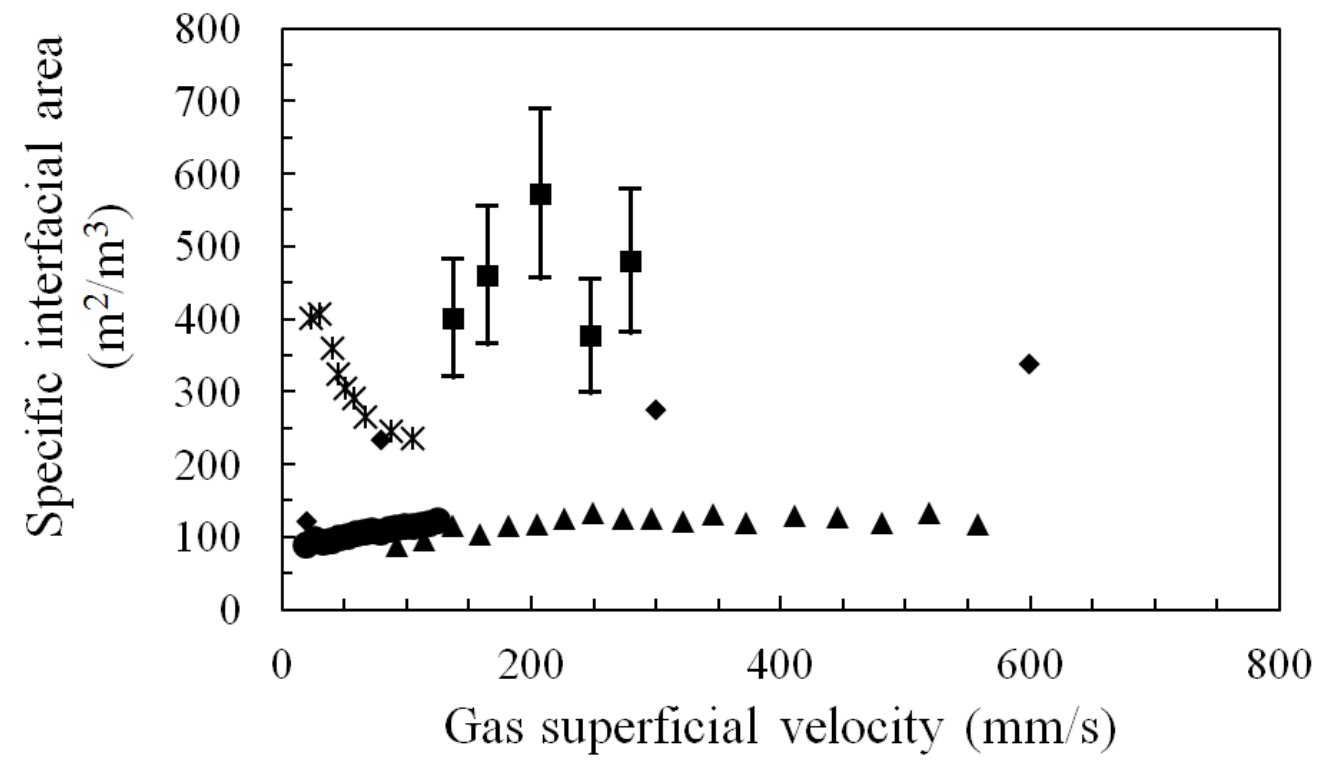




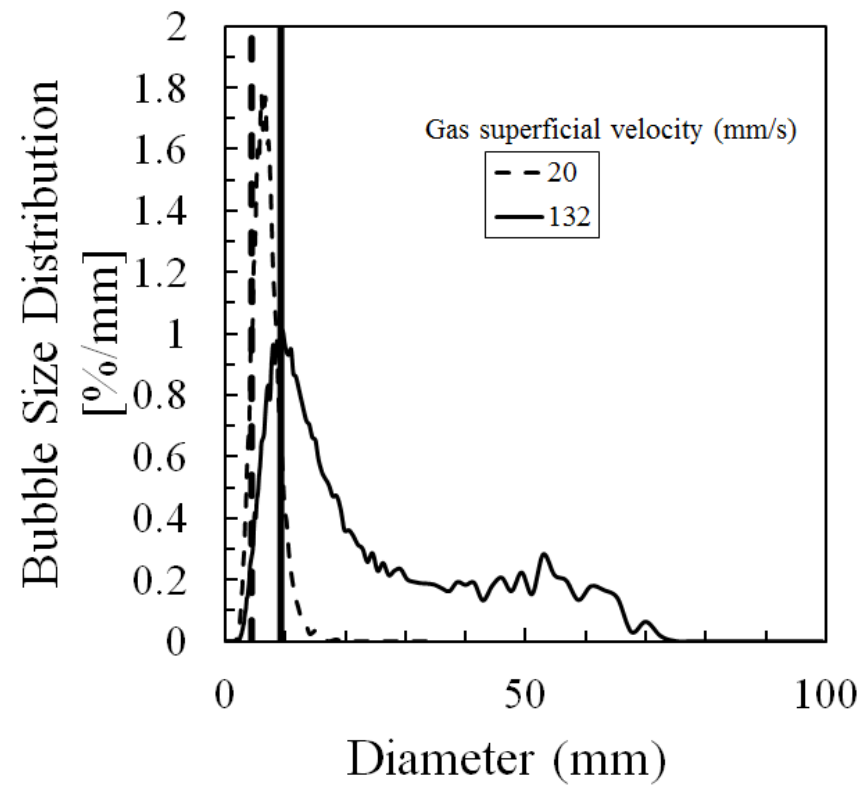

Fig. 20 Bubble size distribution obtained from WMS measurements [51]. Liquid silicone oil (see Table 3 for physical properties). Vertical lines are predictions of bubble diameter at formation at air injection orifices [28].

It is values were calculated by integration of these. In contrast, the silicone oil work [51], has values of specific interfacial area which is nearly an order of magnitude lower. Given the similarity between the values of void fraction between all the data sets, it is obvious that these lower values of specific interfacial area must be caused by larger bubble sizes. It is known [28] that bubble sizes increase with increasing viscosity. For this particular liquid bubble sizes have been measured. Examples of the distribution of sizes are shown in Fig. 20 for the lowest and highest gas superficial velocities studied. The vertical lines are the bubble diameter predicted from the equation of Gaddis and Vogelpohl [28] which is reasonably close to the main peak of each distribution. These sizes are those created at the distributor, the larger bubbles present are from the process of coalescence.

\section{Conclusions}


From the experimental data and discussion presented above, it can be concluded that the aqueous solution of glycerol and potassium chloride can be employed as an analogue for the hydrodynamics of a bubble column, which it is intended to operate with ionic liquids. This is useful for scale up experiments given the high cost of sourcing or synthesising ionic liquids.

The suitability of the analogue liquid is judged on the following parameters: mean gas hold-up; time-varying gas hold-up; lengths of Taylor bubbles and liquid slugs and specific interface area.

The behaviour of Taylor bubbles is complicated by their coalescing with preceding ones. The process can be very sudden and during it there are very much distorted bubbles present. This can take the form of a very thin liquid membrane. This Taylor bubble coalescence has been reported, e.g., [61] before but not to the level of detail reported here

\section{Acknowledgements}

This work was carried out as part of EPSRC Grant EP/E004644/1. The authors would like to thank Professor S. Hosakawa (Kobe University, Japan) for his assistance in the determination of bubble sizes.

\section{References}

[1] V.I. Parvulescu, C. Hardacre, Catalysis in ionic liquids, Chem. Rev. 107 (2007) 2615-2665.

[2] T. Welton, Ionic liquids in catalysis, Coord. Chem. Rev. 248 (2004) 2459-2477.

[3] P. Wassercheid, T. Welton, Ionic liquids in synthesis, Wiley-VCH: Weinheim, Germany (2008).

[4] N. Jain, A. Kumar, S. Chauhan, S.M.S. Chauhan, Chemical and biochemical transformations in ionic liquids, Tetrahedron 61 (2005) 1015-1060.

[5] F. Endres, Ionic liquids: Promising solvents for electrochemistry, Z. Phys. Chem. 218 (2004) 255.

[6] M. Koel, Ionic liquids in chemical analysis, Crit. Rev. Anal. Chem. 35 (2005) 177192.

[7] H. Zhao, S.Q. Xia, P.S. Ma, Use of ionic liquids as 'Green' solvents for extractions, J. Chem. Technol. Biotechnol. 80 (2005) 1089-1096. 
[8] M. Antonietti, D.B. Kuang, B. Smarsly, Z. Yong, Ionic liquids for the convenient synthesis of functional nanoparticles and other inorganic nanostructures. Angew. Chem., Int. Ed. 43(2004), 4988-4992.

[9] R. Kaji, D. Zhao, P. Licence, B.J. Azzopardi, Studies of the interaction of ionic liquid and gas in a small diameter bubble column, Ind. Eng. Chem. Res. 48 (2009) 7938-7944.

[10] V. Lange, B.J. Azzopardi, P. Licence, Hydrodynamics of ionic liquids in bubble columns, Chapter 6 in Ionic Liquids - New Aspects for the Future, Ed. Jun-ichi Kadokawa, ISBN 978-953-51-0937-2, 706 pages, Pub. InTech

[11] X. Zhang, H. Dong, Y. Huang, C. Li, X. Zhang, Experimental study on gas holdup and bubble behavior in carbon capture systems with ionic liquid, Chem. Eng. J. 209 (2012) 607-615.

[12] W.D. Deckwer, Bubble column reactors, Wiley: New York, (1992).

[13] H. Jakobsen, Chemical Reactor Modeling. Springer, (2008).

[14] B.J. Azzopardi, R.F. Mudde, S. Lo., H. Morvan, Y. Yan, D. Zhao, Hydrodynamics of Gas-Liquid Reactors: Normal Operation and Upset Conditions, John Wiley \& Sons, Ltd. (2011).

[15] R.F. Mudde, R. F.; H.E.A. Van Den Akker, Dynamic behaviour of the flow field of a bubble column at low to moderate gas fractions, Chem. Eng. Sci. 54 (1999) 49214927.

[16] M.C. Ruzicka, J. Zahradnik, J. Drahos, N.H. Thomas, Homogeneous-heterogeneous regime transition in bubble columns. Chem. Eng. Sci. 56 (2001) 4609-4626.

[17] M.V. Kantak, R.P. Hesketh, B.G. Kelkar, Effect of gas and liquid properties on gas phase dispersion in bubble columns, Chem. Eng. J. 59 (1995) 91-100

[18] B.J. Azzopardi, L. Pioli, L.A. Abdulkareem, The properties of large bubbles rising in very viscous liquids in vertical conduits. Int. J. Multiphase Flow 67 (2014) 160-173.

[19] K. Akita, F. Yoshida, Bubble size, interfacial area, and liquid-phase mass transfer coefficient in bubble columns, Ind. Eng. Chem., Process Des. Develop. 13 (1974) 8491.

[20] J. Zahradnik, M. Fialova, M. Ruzicka, J. Drahos, F. Kastanek, N.H. Thomas, Duality of the gas-liquid flow regimes in bubble column reactors, Chem. Eng. Sci. 52 (1997) 3811-3826.

[21] S. Sharaf, M. Zednikova, M.C. Ruzicka, B.J., Azzopardi, 2016. Global and local hydrodynamics of bubble columns - effect of gas distributor, Chem. Eng. J. 288 (2016) 489-504.

[22] M. Kaji, T. Sawai, K. Mori, M. Iguchi, Behaviours of bubble formation from a bottom porous nozzle bath, Proc. $5^{\text {th }}$ ExHFT, Thessaloniki, Greece, (2001) 1503-1508. 
[23] A.A. Mouza, G.K. Dalakoglou, S.V. Paras, Effect of liquid properties on the performance of bubble column reactors with fine pore spargers, Chem. Eng. Sci. 60 (2005) 1465-1475.

[24] N.A. Kazakis, I.D. Papadopoulos, A.A. Mouza, Bubble columns with fine pore sparger operating in the pseudo-homogeneous regime: Gas hold up prediction and a criterion for the transition to the heterogeneous regime, Chem. Eng. Sci. 62 (2007) 3092-3103.

[25] N.A. Kazakis, A.A. Mouza, S.V. Paras, Experimental study of bubble formation at metal porous spargers: Effect of liquid properties and sparger characteristics on the initial bubble size distribution, Chem. Eng. J. 137 (2008) 265-281.

[26] J.F. Davidson, B.O.G. Schüler, Bubble formation at an orifice in a viscous liquid, Trans I. Chem. Eng. 38 (1960) 144-154.

[27] J.F. Davidson, B.O.G. Schüler, Bubble formation at an orifice in an inviscid liquid, Trans I. Chem. Eng., 38 (1960) 335-342.

[28] E.S. Gaddis, A. Vogelpohl, Bubble formation in quiescent liquids under constant flow conditions, Chem. Eng. Sci. 41 (1986) 97-105.

[29] T.J. Lin, K. Tsuchiya, L.-S. Fan, Bubble flow characteristics in bubble columns at elevated pressure and temperature, AIChE J. 44 (1998) 545-560.

[30] T.Z. Harmathy, Velocity of large drops and bubbles in media of infinite or restricted extent, AIChE J. 6 (1960) 281-288.

[31] R. Clift, J.R. Grace, M.E. Weber, Bubbles Drops and Particles. Academic Press (1978).

[32] R Collins, The effect of a containing cylindrical boundary on the velocity of a large gas bubble in a liquid. J. Fluid Mech. 28 (1967) 97-112.

[33] S.A. Allahwala, O.E. Potter, Rise velocity equation for isolated bubbles and for isolated slugs in fluidized beds, Ind. Eng. Chem. Fundam. 18 (1979) 112-116.

[34] D.T. Dumitrescu, Stromung an einerluftblaseimsenkrechtenrohr, Zietschrift fur Angew. Math. Mech. 23 (1943) 139-149.

[35] R.M. Davies, G.I. Taylor, The mechanics of large bubbles rising through extended liquids and through liquids in tubes, Proc. Roy. Soc. A200 (1950) 375-390.

[36] F. Viana, R. Pardo, R. Yanez, J.L. Trajello, D.D. Joseph, Universal correlation for the rise velocity of long gas bubbles in round pipes, J. Fluid Mech. 494 (2003) 379-398.

[37] D.J. Nicklin, J.O. Wilkes, J.F. Davidson, Two-phase flow in vertical tubes, Trans. I. Chem. Engrs. 40 (1960) 61-68.

[38] S. Guet, G. Ooms, R.V.A. Oliemans, R.F., Mudde, Bubble size effect on low liquid input drift-flux parameters, Chem. Eng. Sci. 59 (2004) 3315-3329. 
[39] J. Philip, J.M. Proctor, K. Nirajan, J.F. Davidson, Gas hold-up and liquid circulation in internal loop reactors containing highly viscous Newtonian and non-Newtonian liquids, Chem. Eng. Sci. 45 (1990) 651-664.

[40] M. Ruzicka, J. Drahos, P.C. Mena, J.A. Teixeira, Effect of viscosity on homogeneousheterogeneous flow regime transition in bubble columns. Chem. Eng. J. 96 (2003) 15.

[41] M.I. Urseanu, R.P.M. Guit, A. Stankiewicz, G. van Kranenberg, J.H.G.G. Lommen, Influence of operating pressure on the gas hold-up on bubble columns of high viscous media. Chem. Eng. Sci. 58 (2003) 697-704.

[42] R. Krishna, M.I. Urseanu, A.J. Dreher, Gas hold-up in bubble columns: Influence of alcohol addition versus operation at elevated pressures. Chem. Eng. Proc., 39 (2000) 371-378.

[43] S. Maalej, B. Benadda, M. Otterbein, Interfacial area and volumetric mass transfer coefficient in a bubble reactor at elevated pressures, Chem. Eng. Sci. 58 (2003) 23652376

[44] R. Maceiras, E. Álvarez, M.A. Cancela, Experimental interfacial area measurements in a bubble column, Chem. Eng. J. 163 (2010) 331-336.

[45] M. D. La Rubia, A. García-Abuín, D. Gómez-Díaz, J.M. Navaza, Interfacial area and mass transfer in carbon dioxide absorption in TEA aqueous solutions in a bubble column reactor, Chem. Eng. Proc. 49 (2010) 852-858

[46] A. Garcia-Abuin, D. Gomez-Diaz, M. Losada, J. M. Navaza, Bubble column gasliquid interfacial area in a polymer + surfactant + water system, Chem. Eng. Sci. 75 (2012) 334-341

[47] X. Jia, W. Hu, X. Yuan, K. Yu, Effect of surfactant type on interfacial area and liquid mass transfer for $\mathrm{CO} 2$ absorption in a bubble column, Chinese J. Chem. Eng. 23 (2015) 476-481

[48] S. García-Salas, M.E. Rosales Peña Alfaro, R. M. Porter, F. Thalasso, Measurement of local specific interfacial area in bubble columns via a non-isokinetic withdrawal method coupled to electro-optical detector, Chem. Eng. Sci. 63 (2008) 1029-1038

[49] D.D. McClure, J.M. Kavanagh, D.F. Fletcher, G.W. Barton, Oxygen transfer in bubble columns at industrially relevant superficial velocities: Experimental work and CFD modelling, Chem. Eng. J. 280 (2015) 138-146

[50] J. Xue, M. Al-Dahhan, M.P. Dudukovic, R. F. Mudde, Bubble velocity, size, and interfacial area measurements in a bubble column by four-point optical probe, AIChE Journal 54 (2008) 350-363. See also J. Xue, Bubble velocity, size and interfacial area measurements in bubble columns, PhD Thesis, Washington University, Saint Louis, Missouri, U.S.A. (2004).

[51] S. Sharaf, Testing and application of wire mesh sensors in vertical gas liquid two-phase flow, PhD Thesis, University of Nottingham (2011). 
[52] M. Fossa, Design and performance of a conductance probe for measuring the liquid fraction in two-phase gas-liquid flows. Flow Meas. Instrum. 9(1998) 103-109.

[53] Gómez, E., B. González, N. Calvar, E. Tojo, Á. Dominguez, Physical properties of pure 1-Ethyl-3-Methulimidazolium Ethylsulphate and its binary mixtures with ethanol and water at several temperatures, J. Chem. Eng. Data 51 (2006) 2096-2102.

[54] D. Broder, M.Sommerfeld, Planar Shadow Image Velocimetry for the Analysis of the Hydrodynamics in Bubbly Flows, Meas. Sci. Tech.18 (2007) 2513-2528

[55] Z. Zhang, K. Suzuki, S. Hosokawa, A. Tomiyama, Motion of Small Bubbles near a Grid Spacer in a Two by Three Rod Bundle, J. Fluid Sci. Tech. 3 (2008) 172-182

[56] S. Hosokawa, K. Tanaka, A. Tomiyama, Y. Maeda, S. Yamaguchi, Y. Ito, Measurement of Micro Bubbles Generated by a Pressurized Dissolution Method, J. Phys.: Conf. Series, 147 (2009)

[57] L. Zhang, M. Shoji, M., Aperiodic bubble formation from a submerged orifice. Chem. Eng. Sci. 56, (2001) 5371-5381.

[58] V.V. Buwa, D. Gerlach, F. Durst, E. Schlücker, Numerical simulations of bubble formation on submerged orifices: Period-1 and period-2 bubbling regimes. . Chem. Eng. Sci. 62 (2007) 7119-7132.

[59] .M.F.R. Pinto, M.N. Coelho Pinheiro, S. Nogueira, V.D. Ferreera, J.B.L.M. Campos, Experimental study on the transition in the velocity of individual Taylor bubbles in vertical upward co-current liquid flow. Chem. Eng. Res. Design 83 (2005) 1103-1110.

[60] H. Chaumat, A.M. Billet, H. Delmas, Hydrodynamics and mass transfer in bubble column: Influence of liquid phase surface tension, Chem. Eng. Sci. 62 (2007) 73787390 .

[61] B.J. Azzopardi, H.K. Do, A. Azzi, V. Hernandez Perez, Characteristics of air/water slug flow in an intermediate diameter pipe. Exp. Therm. Fluid Sci. 60 (2015) 1-8. 


\section{Nomenclature}

Ar $\quad$ Archimedes number $\left.=\rho_{L}^{2} g D_{L}^{3} / \mu_{L}^{2}\right)(-)$

a Specific interfacial area $\left(\mathrm{m}^{2} / \mathrm{m}^{3}\right)$

$C_{0} \quad$ Distribution coefficient (-)

$D_{32} \quad$ Sauter mean diameter (m)

$D_{c} \quad$ Column diameter (m)

$D_{e} \quad$ Spacing between electrodes (m)

$D_{s} \quad$ Porous sinter diameter (m)

$D_{T B} \quad$ Diameter of Taylor bubble (m)

$g \quad$ Gravitational acceleration $\left(\mathrm{m} / \mathrm{s}^{2}\right)$

$L_{s} \quad$ Length of liquid slug (m)

$L_{T B} \quad$ Length of Taylor bubble (m)

$s \quad$ Thickness of electrode (m)

$u_{g s} \quad$ Gas superficial velocity based on column diameter $(\mathrm{m} / \mathrm{s})$

$u_{g s s} \quad$ Gas superficial velocity based on porous sinter diameter $(\mathrm{m} / \mathrm{s})$

$u_{T B} \quad$ Velocity of Taylor bubble $(\mathrm{m} / \mathrm{s})$

$\varepsilon_{g} \quad$ Gas hold-up (-)

$\eta \quad$ Liquid viscosity (Pa s)

$\rho \quad$ Liquid density $\left(\mathrm{kg} / \mathrm{m}^{3}\right)$

$\sigma \quad$ Surface tension $(\mathrm{N} / \mathrm{m})$

Ar Archimedes number, defined in Eq. (4)

Eo Eötvös number, defined in Eq. (4)

Fr Froude number, dimensionless Taylor bubble rise velocity

$\mathrm{Fr}_{\mathrm{s}} \quad$ Froude number based on porous sinter diameter, defined after Eq. (5)

Ka Kapitza number, defined in Eq. (4)

$\operatorname{Re}_{\mathrm{c}} \quad$ Reynolds number based on column diameter

$\operatorname{Re}_{\mathrm{s}} \quad$ Reynolds number based on porous sinter diameter, defined after Eq. (5) 
We $\quad$ Weber number based on porous sinter diameter, defined after Eq. (5) 